Check for updates

Cite this: J. Anal. At. Spectrom., 2020 35,1167

Received 17th September 2019 Accepted 5th May 2020

DOI: 10.1039/c9ja00315k rsc.li/jaas

\section{Zirconium stable isotope analysis of zircon by MC- ICP-MS: methods and application to evaluating intra-crystalline zonation in a zircon megacryst}

\author{
Hannah G. D. Tompkins, (D)*ab Lisa J. Zieman, (D) a Mauricio Ibañez-Mejia (D) ${ }^{a}$ \\ and François L. H. Tissot iD b
}

Zirconium ( $\mathrm{Zr}$ ) plays a key role in the development of phases like zircon $\left(\mathrm{ZrSiO}_{4}\right)$ and baddeleyite $\left(\mathrm{ZrO}_{2}\right)$ in magmatic systems. These minerals are crucial for the study of geologic time and crustal evolution, and their high resistivity to weathering and erosion results in their preservation on timescales of billions of years. Although zircon and baddeleyite may also preserve a robust record of Zr isotope behavior in hightemperature terrestrial environments, little is known about the factors that control Zr isotope partitioning in magmatic systems, the petrogenetic significance of fractionated compositions, or how these variations are recorded in Zr-rich accessory phases. Here, we describe a new analytical protocol for accurately determining the $\mathrm{Zr}$ stable isotope composition of zircon by multicollector-inductively coupled plasma-mass spectrometry (MC-ICP-MS), using the double-spike method to correct for procedural and instrumental mass bias. We apply this technique to test whether zircon crystallization in carbonatite magmatic systems is a driver of $Z r$ isotope fractionation by interrogating the internal zonation of a zircon megacryst from the Mud Tank carbonatite (MTUR1). We find the MTUR1 megacryst to lack internal zoning within analytical uncertainties with a mean $\mu^{94 / 90} \mathrm{Zr}_{\text {NIST }}=-55 \pm 28 \mathrm{ppm}$ (2 SD, $n=151$ ), which suggests that zircon crystallization is not a driver of $\mathrm{Zr}$ isotope fractionation in carbonatite magmas. This observation is in stark contrast with those made in silicate magmatic systems, raising the possibility that the bonding environment of $\mathrm{Zr}^{4+}$ ions may be fundamentally different in carbonatite vs. silicate melts. Because of its remarkable homogeneity, the MTUR1 megacryst is an ideal natural reference material for $\mathrm{Zr}$ isotopic analysis of zircon using both solution and spatially resolved methods. The reproducibility of a pure $\mathrm{Zr}$ solution and our chemically purified zircon fractions indicate that the external reproducibility of our method is on the order of $\pm 28 \mathrm{ppm}$ for $\mu^{94 / 90} \mathrm{Zr}$, or $\pm 7 \mathrm{ppm}$ per amu, at $95 \%$ confidence.

\section{Introduction}

Zirconium is geochemically classified as a High Field Strength Element (HFSE), a group of transition metals that play a fundamental role in studying the differentiation of magmatic systems and understanding the co-evolution of Earth's mantle and crust (e.g., (ref. 1-8)). Although mass-independent (e.g., nucleosynthetic and radiogenic) variations in $\mathrm{Zr}$ isotopic composition have been extensively studied in extra-terrestrial and some terrestrial materials (e.g., (ref. 9-19)), massdependent variations remain comparatively poorly studied and understood..$^{\mathbf{2 0}-24}$ Therefore, elucidating the mechanisms responsible for the partitioning of $\mathrm{Zr}$ isotopes amongst minerals and liquids in magmatic environments will be

${ }^{a}$ Department of Earth and Environmental Sciences, University of Rochester, Rochester, NY14627, USA. E-mail: htompkin@ur.rochester.edu

${ }^{b}$ The Isotoparium, Division of Geological and Planetary Sciences, California Institute of Technology, Pasadena, CA 91125, USA fundamental for interpreting the petrogenetic significance of fractionated isotopic compositions.

According to first principles of stable isotope fractionation theory, heavy isotopes tend to preferentially occupy configurations with shorter bond lengths and lowest coordination state at thermodynamic equilibrium. ${ }^{25,26}$ Therefore, when Zr-rich phases like zircon and baddeleyite crystallize from a silicate melt, shifts in the coordination state of $\mathrm{Zr}^{4+}$ ions from 6-fold in the liquid $^{27,28}$ to 8 - and 7 -fold in zircon ${ }^{29}$ and baddeleyite, ${ }^{30}$ respectively, have the potential to result in stable isotope fractionation. The expectation is that due to the higher coordination of $\mathrm{Zr}$ ions and longer $\mathrm{Zr}-\mathrm{O}$ bond lengths in zircon ${ }^{29}$ and baddeleyite $^{30}$ relative to the melt, ${ }^{27,28}$ these phases are likely to preferentially incorporate lighter $\mathrm{Zr}$ isotopes as they crystallize from a liquid.

Initial investigations of $\mathrm{Zr}$ stable isotope fractionation in magmatic systems, however, have resulted in conflicting observations. Studies of bulk igneous rocks ${ }^{20,21}$ interpreted a positive correlation between increasingly 'heavy' $\mathrm{Zr}$ isotopic composition and $\mathrm{SiO}_{2} \mathrm{wt} \%$ as being due to the removal of 
isotopically light zircon $^{21}$ during magma differentiation. In contrast, a detailed study of single zircon and baddeleyite crystals from a closed igneous system has shown that these $\mathrm{Zr}$ rich phases are isotopically heavy relative to the co-existing melt. ${ }^{23}$ These results not only point to opposite directions of isotope fractionation, but also show that the very hypothesis that $\mathrm{Zr}$ isotope variability in magmas can be driven by zircon crystallization is yet to be fully tested and understood. One approach to resolve this discrepancy is to determine the intracrystalline zonation of zircon: if this phase is indeed driving $\mathrm{Zr}$ isotopic fractionation in a crystallizing magma via a Rayleightype mechanism, ${ }^{21,23}$ then zircon crystals should develop an internal zonation that records the compositional change of the melt as concurrent crystallization and fractionation take place.

Here, we describe a new analytical technique for the highprecision and accuracy analysis of mass-dependent $\mathrm{Zr}$ isotope variability in zircon using the double-spike MC-ICP-MS technique, and apply it to evaluate the intra-crystalline zoning of a zircon megacryst from the Mud Tank carbonatite. ${ }^{31,32} \mathrm{We}$ also present results for the widely used 91500 zircon geostandard. ${ }^{33}$ In addition to testing the hypothesis that zircon crystallization may be a driver of $\mathrm{Zr}$ isotope fractionation in carbonatite magmatic systems, we show that: (i) our method is capable of determining $\mathrm{Zr}$ isotope compositions in zircon that are accurate and precise to within \pm 7 ppm per amu at the single measurement level, and (ii) that the megacryst studied here (MTUR1) is a valuable primary reference material for $\mathrm{Zr}$ isotope analyses of zircon, both by solution and spatially-resolved (e.g., SIMS and LA-ICP-MS) analytical methods.

\section{Materials and methods}

\section{Preparation of a ${ }^{91} \mathrm{Zr}-{ }^{96} \mathrm{Zr}$ double spike}

For elements with four isotopes or more, the double-spike (DS) technique is the method of choice for performing high-accuracy measurements of mass-dependent isotopic variations (e.g., (ref. 34-38)), as it allows for correction of instrumental mass-bias and fractionation during sample preparation. Three main criteria influence the choice of the two isotopes to spike and the four isotopes to use for inversion of the non-linear system of equations of the DS method: (i) the composition of the samplespike mixture should minimize the uncertainty on $\alpha$, the fractionation factor between the standard and the sample; (ii) slight variations in the sample-to-spike ratio should not lead to significant loss of precision and/or accuracy (i.e., robustness of the spike); (iii) isotopes whose abundance are affected by massindependent effects should be avoided, as the DS method assumes that the relative abundances of all isotopes used for inversion are exclusively related to each other massdependently.

The 'double-spike toolbox ${ }^{39}$ indicates that the most precise measurements of $\mathrm{Zr}$ isotopes are obtained using a ${ }^{91} \mathrm{Zr}-{ }^{96} \mathrm{Zr}$ DS along with ${ }^{90} \mathrm{Zr}$ and ${ }^{94} \mathrm{Zr}$ for inversion (see supplementary materials of Rudge et al. $\left.{ }^{39}\right)$. Although a ${ }^{92} \mathrm{Zr}-{ }^{96} \mathrm{Zr}$ DS can in theory be comparably robust, it is not ideal due to the potential of radiogenic ${ }^{92} \mathrm{Zr}$ anomalies from decay of short-lived ${ }^{92} \mathrm{Nb}$ (e.g., (ref. 13, 14 and 19)). Enriched isotopic materials were obtained from TRACE Sciences International (www.tracesciences.com) in oxide form for ${ }^{91} \mathrm{Zr}$ (>90\% purity) and ${ }^{96} \mathrm{Zr}(>86 \%)$. Using the approximate isotopic composition of the primary single spikes (certified by the vendor) as input, we utilized the "double spike toolbox ${ }^{39}$ MATLAB ${ }^{39}$ package to estimate the DS composition that would minimize the uncertainty of $\alpha$. This preliminary modelling indicated that a $0.43: 0.57$ DS : sample mixture, using a ${ }^{91} \mathrm{Zr}-{ }^{96} \mathrm{Zr}$ spike prepared in $0.49: 0.51$ proportions, would be optimal (blue curve in Fig. 1a).

Isotopically enriched oxides were loaded into pre-cleaned perfluoroalkoxy alkane (PFA) beakers, submerged in $5 \mathrm{ml}$ of a 3:1 mixture of ultra-pure concentrated $\mathrm{HF}$ and $\mathrm{HNO}_{3}$ and placed on a hot plate at $150{ }^{\circ} \mathrm{C}$ for one week to ensure complete digestion. The concentrated single spikes were then diluted to $\sim 120 \mathrm{ml}$ of $3 \mathrm{M} \mathrm{HNO}_{3}+0.5 \mathrm{M} \mathrm{HF}$ in pre-cleaned fluorinated ethylene propylene (FEP) bottles. Concentrations of ${ }^{91} \mathrm{Zr}$ and ${ }^{96} \mathrm{Zr}$ in the single spikes were determined using the standard addition method relative to a gravimetric solution prepared at the University of Rochester Laboratory for Isotope Geochemistry (UR-LIG) from high-purity $\mathrm{Zr}$ metal. Once the concentrations of the single spikes were known, these were mixed in the proportions needed to produce a DS of optimal composition.
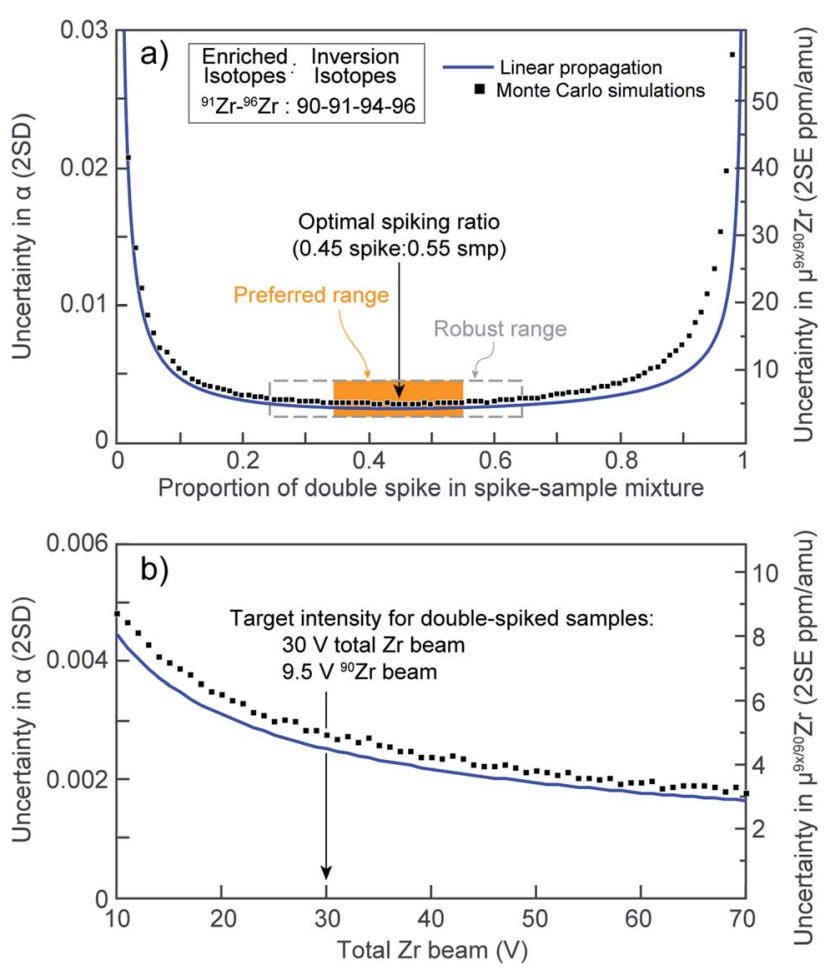

Fig. 1 (a) Uncertainty in the sample-standard fractionation factor, $\alpha$, as a function of the spike-to-sample ratio for the double spike used in this work. Orange box represents the preferred spiking range $( \pm 10 \%)$ and gray dashed box the 'robust' spiking range ( $\pm 20 \%$ ). (b) Expected uncertainty on $\mathrm{Zr}$ stable-isotope analyses using the optimum ${ }^{91} \mathrm{Zr}-{ }^{96} \mathrm{Zr}$ double spike as a function of the total $\mathrm{Zr}$ beam intensity (in V). Blue curves: calculations performed using single spike compositions as input and the code of Rudge et al. ${ }^{39}$ Black squares: Monte Carlo simulations performed using our calibrated double-spike composition and our data processing algorithm. 
Calibration of the DS was performed against the $\mathrm{Zr}_{\mathrm{NIST}}$ standard (see details below), by measuring the pure spike and pure standard as well as 9 standard-DS mixtures spaced every $10 \%$ in proportion (e.g. , (ref. 34, 39-42)). The calculated isotopic composition of the DS is shown in Table 1. Once calibrated for its isotopic composition, the concentration of the DS was determined by reverse isotope dilution using the same gravimetric solution used for establishing the concentration of the single spikes.

\section{Spike optimization}

After DS calibration, further optimization was performed to determine the best sample:spike proportion that would minimize the uncertainty on $\alpha$, evaluate the potential impact of variable spiking ratios, and determine the beam intensity needed to achieve the desired measurement precision. Optimizations were performed numerically on MATLAB ${ }^{\circledR}$ using Monte Carlo simulations, such that our calibrated DS and data inversion code could be compared to the expectations from the linear error propagation modelling done using the 'double spike toolbox ${ }^{39}$ prior to spike mixing.

Synthetic spike : standard mixtures ranging from $1 \%$ to $99 \%$ spike in $1 \%$ increments were computed numerically, using the composition of our standard and DS. Relative abundances of each isotope in the mixtures were converted to mean beam intensities by setting the total $\mathrm{Zr}$ beam to $30 \mathrm{~V}$ in each case, and standard deviations for each beam were calculated as the quadratic sum of the Johnson-Nyquist (i.e., thermal) noise and counting statistics ${ }^{39,41}$ using the following expression:

$$
\sigma_{\text {beam }}{ }^{2}=(4 k T R+\bar{V} e R) / \Delta t
$$

where $k$ is the Boltzmann constant $\left(1.380649 \times 10^{-23} \mathrm{~J} \mathrm{~K}^{-1}\right), T$ is the absolute temperature (set to $319 \mathrm{~K}$ ), $R$ is the resistivity of the collector amplifiers (set to $1 \times 10^{11} \mathrm{ohm}$ ), $V$ is the mean voltage measured on the collector (in $\mathrm{V}$ ), $e$ is the elementary charge $\left(1.602176634 \times 10^{-19} \mathrm{C}\right)$, and $\Delta t$ is the integration time of our acquisition method (set to $4.192 \mathrm{~s}$ ). Once the mean intensities and standard deviations of each beam in each mixture were calculated, 3000 synthetic integrations were simulated for each mixture as a normal random distribution and then processed using the same double spike inversion code we developed to reduce our data.

Results of this numerical optimization are shown in Fig. 1a (black squares), where they are compared with expectations from the linear uncertainty propagations performed using the 'double-spike toolbox' ${ }^{39}$ (blue curve). The agreement between both approaches is excellent, showing that our DS composition is optimal. Close inspection of the Monte Carlo simulations

Table 1 Calibrated isotopic composition of our $\mathrm{Zr}$ double spike

\begin{tabular}{llccc}
\hline & ${ }^{91} \mathrm{Zr} /{ }^{90} \mathrm{Zr}$ & ${ }^{92} \mathrm{Zr} /{ }^{90} \mathrm{Zr}$ & ${ }^{94} \mathrm{Zr} /{ }^{90} \mathrm{Zr}$ & ${ }^{96} \mathrm{Zr} /{ }^{90} \mathrm{Zr}$ \\
\hline Double spike & 8.169497 & 0.535834 & 0.430748 & 8.355763 \\
\pm 2 se (abs) & 0.000017 & 0.000008 & 0.000006 & 0.000102 \\
\pm 2 se (ppm) & 2 & 15 & 13 & 12
\end{tabular}

indicates that: (i) the optimal spike to sample ratio for minimizing the uncertainty on $\alpha$ is $0.45: 0.55$, which is within $2 \%$ agreement of the linear propagation model; and (ii) there is only minimal uncertainty amplification for inaccurate spiking proportions within a $\pm 20 \%$ range ( $\leq 1 \mathrm{ppm}$ per amu), and completely negligible effects within $\pm 10 \%$ ( $c a$. 0.2 ppm per amu). Thus, our DS should remain highly robust when spiking ratios are within $\pm 20 \%$ of the targeted proportion (dashed box, Fig. 1a), while the effects of a $\pm 10 \%$ spiking inaccuracy would be negligible (orange box, Fig. 1a).

Lastly, in order to determine the total beam intensity at which samples need to be analyzed to achieve optimal precision, additional uncertainty propagation simulations were performed by varying the total $\mathrm{Zr}$ beam intensity at a constant (optimal) spike : sample ratio. The results are shown in Fig. 1b. Calculations performed with the 'double-spike toolbox' ${ }^{39}$ and our own Monte Carlo and inversion codes are in excellent agreement, and indicate that uncertainty on $\alpha$ decreases rapidly as the total $\mathrm{Zr}$ beam increases from $10 \mathrm{~V}$ to $\mathrm{ca}$. $30 \mathrm{~V}$. Above $30 \mathrm{~V}$, large increases in intensity are only accompanied by moderate improvements in precision. Therefore, to minimize $\mathrm{Zr}$ concentrations in the measured solutions, wash-out times and the likelihood of memory effects in the sample introduction system, a total beam intensity of $c a .30 \mathrm{~V}$ was used in this study. This translates to approximately $9.5 \mathrm{~V}$ of ${ }^{90} \mathrm{Zr}$, which at $\sim 32 \%$ is the most abundant isotope in our DS-sample mixtures.

\section{Zircon samples studied}

A single zircon (tetragonal $\mathrm{ZrSiO}_{4}$ ) megacryst from the $\sim 732 \mathrm{Ma}$ Mud Tank carbonatite of Australia,,$^{31,32,43}$ hereafter referred as MTUR1, was obtained commercially, cast in epoxy resin, and sliced in half parallel to the $c$-axis using a low-speed saw to expose an internal section. One face of the sliced crystal was polished to a high-quality finish using $0.25 \mu \mathrm{m}$ diamond paste and imaged by cathodoluminescence (CL; Fig. 2) using a Deben panchromatic detector mounted on a JEOL 7100FT Field Emission Scanning Electron Microscope in the Mackay Microbeam Laboratory at University of Nevada, Reno. Using the CL mosaic as a guide, 18 fragments of the crystal were carefully micro-drilled along a rim-core-rim transect (Fig. 2), using a hollow diamond drill-bit of $0.5 \mathrm{~mm}$ internal diameter that was custom manufactured by UKAM industrial superhard tools. Individual cores extracted from this megacryst were $\sim 500 \mu \mathrm{m}$ in diameter by $500 \mu \mathrm{m}$ in depth.

Several small fragments of the 91500 zircon,,$^{33}$ a widely-used geostandard in the isotope geochemistry literature, were also individually picked for analysis. All samples were processed in a clean laboratory environment at the UR-LIG, as described below.

\section{Zircon cleaning, chemical abrasion and dissolution}

Each zircon fragment was rinsed twice in Milli-Q water and acetone before being transferred to individual fused quartz crucibles and placed in a muffle furnace at $900{ }^{\circ} \mathrm{C}$ for 60 hours. This thermal annealing step heals the short-range order of low to moderately radiation damaged zircon domains while leaving high-dose domains unhealed. ${ }^{\mathbf{4 4 , 4 5}}$ 


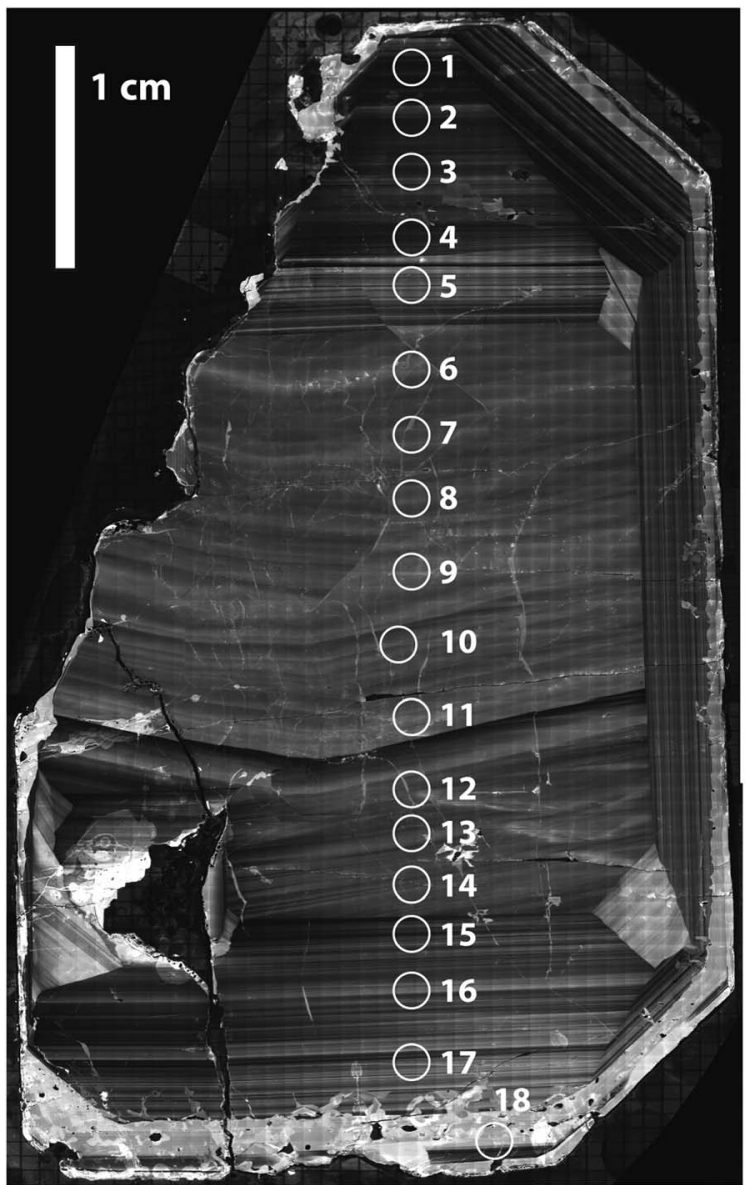

Fig. 2 Cathodoluminescence mosaic of a sliced face of the Mud Tank zircon megacryst MTUR1, showing internal oscillatory zoning and approximate location of micro-drilled samples.

Thermally annealed fragments were carefully pipetted into 200 $\mu \mathrm{l}$ PFA microcapsules along with $c a .10 \mu \mathrm{l}$ of $\mathrm{MQ}-\mathrm{H}_{2} \mathrm{O}$ and submerged in ca. $100 \mu \mathrm{l}$ of $29 \mathrm{M}$ HF. Microcapsules were then placed inside a large-capacity Parrß acid digestion vessel and zircon leaching (i.e., 'chemical abrasion') was performed at $215^{\circ} \mathrm{C}$ for 12 hours. This chemical attack preferentially removes inclusions and zircon domains with moderate to high radiation damage that may have behaved as chemically open systems after zircon crystallization, ${ }^{45}$ in addition to removing any 'blank' contributions from handling and micro-coring. The remaining solids (i.e., chemically abraded residues) were transferred into pre-cleaned $7 \mathrm{ml}$ vials and thoroughly rinsed twice in $\mathrm{MQ} \mathrm{H}_{2} \mathrm{O}$, fluxed on a hot plate at $90{ }^{\circ} \mathrm{C}$ using ultrapure $6.2 \mathrm{M} \mathrm{HCl}$, and rinsed again thrice in $\mathrm{MQ} \mathrm{H}_{2} \mathrm{O}$. The cleaned chemically abraded residues were loaded back into pre-cleaned microcapsules and fully dissolved using $c a .100 \mu \mathrm{l}$ of ultra-pure $29 \mathrm{M} \mathrm{HF}$ and trace $\mathrm{HNO}_{3}$ at $215^{\circ} \mathrm{C}$ for 48 hours in a high-capacity Parr® acid digestion vessel.

\section{Concentration measurements and spiking}

After complete zircon dissolution was achieved, the sample solutions ( $c a .100 \mu \mathrm{l}$ of $29 \mathrm{M} \mathrm{HF}$ ) were transferred into pre-cleaned $7 \mathrm{ml}$ PFA beakers containing $1 \mathrm{ml}$ of $0.59 \mathrm{M} \mathrm{HNO}_{3}+0.28 \mathrm{M} \mathrm{HF}$. The solution was allowed to mix thoroughly on a hot plate at $120^{\circ} \mathrm{C}$ for
48 hours prior to aliquoting for concentration measurements. Aliquots of $50 \mu \mathrm{l}$ ( $5 \%$ of sample) were taken from each solution and diluted with $950 \mu \mathrm{l}$ of $0.48 \mathrm{M} \mathrm{HNO}_{3}+0.25 \mathrm{M} \mathrm{HF}+2 \mathrm{ppb}$ In. Concentration measurements were performed on an Agilent 7900 quadrupole ICP-MS at the University of Rochester using In as an internal standard for drift correction.

After $\mathrm{Zr}$ concentration measurements, aliquots containing approximately $340 \mathrm{ng}$ of natural $\mathrm{Zr}$ were pipetted from each sample, transferred into pre-cleaned $7 \mathrm{ml}$ PFA beakers, and mixed with $260 \mathrm{ng} \mathrm{Zr}$ from the ${ }^{91} \mathrm{Zr}-{ }^{96} \mathrm{Zr}$ DS to achieve optimal spike : sample proportions of $0.45: 0.55$ (Fig. 1). Spiked aliquots were fluxed at $140{ }^{\circ} \mathrm{C}$ on a hotplate overnight, dried down to a salt, re-digested in $1 \mathrm{ml}$ of $12 \mathrm{M} \mathrm{HCl}$, dried down one more time, and re-digested in $1 \mathrm{ml}$ of $6 \mathrm{M} \mathrm{HCl}+$ $0.06 \mathrm{M}$ HF for chromatographic purification. Complete spikesample equilibration prior to chemical purification is vital for obtaining accurate isotopic results (e.g., (ref. 46)). Mixing the spike and sample using the same solution matrix, followed by consecutive drying steps during acid conversion before ion-exchange chemistry, ensures that spike-sample equilibration is achieved.

\section{Chromatographic purification of $\mathrm{Zr}$}

Although $\mathrm{Zr}$ represents $c a .50 \mathrm{wt} \%$ in the zircon structure, the variable yet non-negligible trace element contents that are typical in natural crystals (e.g., Hf, U, Th, REE, Ti, Mo) may be problematic for high-accuracy $\mathrm{Zr}$ stable isotope measurements due to spectral interferences (Table 2) and/or matrix effects during mass spectrometry. Of these, $\mathrm{Hf}$ and Mo are of particular concern. With typical $\mathrm{HfO}_{2}$ contents on the order of 1 to $2 \mathrm{wt} \%,{ }^{5,23,47} \mathrm{Hf}$ is by far the most abundant trace element in natural zircon. If not removed prior to analysis, the production of ${ }^{180} \mathrm{Hf}^{++}$species may introduce non-systematic interferences on ${ }^{90} \mathrm{Zr}^{+}$. Molybdenum, although only present in low concentrations in the zircon structure, has in some Proterozoic zircon been shown to have isotopic compositions that deviate significantly from 'normal'. ${ }^{48,49}$ This is particularly problematic because Mo isobaric interference corrections, which rely on the assumption of a 'normal' Mo composition (e.g., IUPAC $\left.{ }^{50}\right)$, would be unlikely to be accurate. Therefore, to ensure both precise and accurate $\mathrm{Zr}$ isotope determinations, trace elements, particularly $\mathrm{Hf}$ and $\mathrm{Mo}$, must be removed from the sample solutions prior to MC-ICP-MS measurement.

Zirconium purification was achieved using a two-column procedure, modified after Münker et al..$^{51}$ and optimized at the UR-LIG to improve purity, yields, and separation of $\mathrm{Zr}$ from Mo, Ru and Hf (Table 3; Fig. 3). The first column step used $\sim 190 \mu \mathrm{l}$ of Eichrom Ln-Spec resin ( 25 to $50 \mu \mathrm{m}$ mesh) in custom-made FEP columns $(L=6 \mathrm{~cm}, \phi=2 \mathrm{~mm})$. Elution curves were calibrated and samples were processed using an Eichrom vacuum box to enhance liquid flow and decrease elution times. Flow rates were kept below $\sim 50 \mu \mathrm{l}$ per minute to avoid sample-resin disequilibrium effects. The second step utilized gravity driven flow and $50 \mu \mathrm{l}$ of Bio-Rad AG1-X8 resin (100 to $200 \mu \mathrm{m}$ mesh), using custommade FEP 'micro-columns' $(L=1.6 \mathrm{~cm}, \phi=2 \mathrm{~mm})$. For all separations, new (pre-cleaned) resin was loaded onto the columns 
Table 2 Nu Plasma II and Neptune Plus cup configurations used in this study. IUPAC Zr and Mo fractional isotope abundances (with uncertainties in parentheses) are shown, as well as relevant atomic and molecular spectral interferences that must be minimized for high-accuracy Zr isotope measurements (modified and expanded after Schönbächler et al. ${ }^{71}$ ). Interferences are color-coded as follows: critical isobaric interferences caused by singly charged isotopes (red); important doubly charged or molecular species (oxides and argides; black); other minor molecules (grey). The importance of poly-atomic interferences is based on the abundance of the metal isotope forming the interfering molecule

\begin{tabular}{|c|c|c|c|c|c|c|c|c|c|}
\hline Nu Plasma Cup configuration $\rightarrow$ & L4 & L2 & $A x$ & $\mathrm{H} 2$ & $\mathrm{H} 4$ & H6 & $\mathrm{H7}$ & & $\mathrm{H} 9$ \\
\hline Neptune + Cup configuration $\rightarrow$ & $\stackrel{\mathrm{L} 4}{90}$ & $\stackrel{L 3}{L 3}$ & $\stackrel{\mathrm{L} 2}{92}$ & $\stackrel{\mathrm{L1}}{\mathrm{L}}$ & $\begin{array}{c}\text { Ax } \\
947 r\end{array}$ & ${ }_{95}^{\mathrm{H} 1}$ & $\begin{array}{l}\mathrm{H} 2 \\
96 \\
9 \mathrm{r}\end{array}$ & $\begin{array}{c}\mathrm{H} 3 \\
97\end{array}$ & $\stackrel{\mathrm{H} 4}{98}$ \\
\hline $\begin{array}{l}\text { IUPAC abundance } \rightarrow \\
\text { Type of interference } \downarrow\end{array}$ & $0.5145(40)$ & $0.1122(5)$ & $0.1715(8)$ & 1 & $0.1738(28)$ & $0.1584(11)$ & $0.0280(9)$ & $\begin{array}{c}0.0960(14) \\
\text { Not meas }\end{array}$ & $0.2439(37)$ \\
\hline Atomic (isobars) & & & ${ }^{92} \mathrm{Mo}$ & & ${ }^{94} \mathrm{Mo}$ & & $\begin{array}{l}{ }^{96} \mathrm{Mo} \\
{ }_{96} \mathrm{Ru}\end{array}$ & & ${ }^{98} \mathrm{Ru}$ \\
\hline Doubly charged & ${ }^{180} \mathrm{Hf}^{++}$ & ${ }^{182} W^{++}$ & ${ }^{184} \mathrm{~W}^{++}$ & & ${ }^{188} \mathrm{Os}^{++}$ & ${ }^{190} \mathrm{Os}^{++}$ & ${ }^{192} \mathrm{Os}^{++}$ & & ${ }^{196} \mathrm{Pt}^{++}$ \\
\hline Oxides: & ${ }^{74} \mathrm{Ge}^{16} \mathrm{O}$ & ${ }^{75} \mathrm{As}^{16} \mathrm{O}$ & $\begin{array}{l}{ }^{76} \mathrm{Ge}^{16} \mathrm{O} \\
{ }^{76} \mathrm{Se}^{16} \mathrm{O}\end{array}$ & & ${ }^{78} \mathrm{Se}^{16} \mathrm{O}$ & & ${ }^{80} \mathrm{Se}^{16} \mathrm{O}$ & & ${ }^{82} \mathrm{Se}^{16} \mathrm{O}$ \\
\hline Argides & $\begin{array}{l}{ }^{50} \mathrm{Ti}^{40} \mathrm{Ar} \\
{ }^{50} \mathrm{Cr}^{40} \mathrm{Ar}\end{array}$ & ${ }^{51} \mathrm{~V}^{40} \mathrm{Ar}$ & ${ }^{52} \mathrm{Cr}^{40} \mathrm{Ar}$ & & $\begin{array}{l}{ }^{54} \mathrm{Fe}^{40} \mathrm{Ar} \\
{ }^{54} \mathrm{Cr}^{40} \mathrm{Ar} \\
{ }^{40} \mathrm{Ar}_{2}{ }^{14} \mathrm{~N}\end{array}$ & ${ }^{55} \mathrm{Mn}^{40} \mathrm{Ar}$ & $\begin{array}{l}{ }^{56} \mathrm{Fe}^{\mathbf{4 0}} \mathbf{A r} \\
{ }^{40} \mathrm{Ar}_{2}{ }^{16} \mathrm{O}\end{array}$ & & ${ }^{58} \mathrm{Ni}^{40} \mathrm{Ar}$ \\
\hline
\end{tabular}

Table 3 Column chemistry procedures for Zr chemical purification

\begin{tabular}{|c|c|c|}
\hline Step & Reagent volume & Reagent \\
\hline \multicolumn{3}{|c|}{$\begin{array}{l}\text { Column 1: Eichrom Ln-Spec, } 20-50 \mu \mathrm{m} \text { mesh } \sim 190 \mu \mathrm{l} \text { resin volume (ca. } \\
6.0 \times 0.2 \mathrm{~cm})\end{array}$} \\
\hline Clean & $2 \mathrm{ml}$ & $2 \mathrm{M} \mathrm{HF}$ \\
\hline Clean & $2 \mathrm{ml}$ & $\mathrm{MQ}-\mathrm{H}_{2} \mathrm{O}$ \\
\hline Condition & $1.5 \mathrm{ml}$ & $6 \mathrm{M} \mathrm{HCl}-0.06 \mathrm{M} \mathrm{HF}$ \\
\hline Load & $1.0 \mathrm{ml}$ & $6 \mathrm{M} \mathrm{HCl}-0.06 \mathrm{M} \mathrm{HF}$ \\
\hline Rinse REE & $3.0 \mathrm{ml}$ & $6 \mathrm{M} \mathrm{HCl}-0.06 \mathrm{M} \mathrm{HF}$ \\
\hline $\mathrm{Zr}$ & $11 \mathrm{ml}$ & $6 \mathrm{M} \mathrm{HCl}-0.06 \mathrm{M} \mathrm{HF}$ \\
\hline $\mathrm{Hf}$ & $2.0 \mathrm{ml}$ & $2 \mathrm{M} \mathrm{HF}$ \\
\hline
\end{tabular}

Column 2: Bio-Rad AG1-X8, 100-200 $\mu \mathrm{m}$ mesh $\sim 50 \mu \mathrm{l}$ stem volume (ca. $1.6 \times 0.2 \mathrm{~cm})$

$\begin{array}{lll}\text { Clean } & 1.0 \mathrm{ml} & 6 \mathrm{M} \mathrm{HNO}_{3}-0.2 \mathrm{M} \mathrm{HF} \\ \text { Clean } & 1.0 \mathrm{ml} & 6 \mathrm{M} \mathrm{HCl}-0.06 \mathrm{M} \mathrm{HF} \\ \text { Clean } & 1.0 \mathrm{ml} & \mathrm{MQ}-\mathrm{H}_{2} \mathrm{O} \\ \text { Condition } & 0.5 \mathrm{ml} & 6 \mathrm{M} \mathrm{HCl}-0.06 \mathrm{M} \mathrm{HF} \\ \text { Load } & 0.23 \mathrm{ml} & 6 \mathrm{M} \mathrm{HCl}-0.06 \mathrm{M} \mathrm{HF} \\ \mathrm{Zr} & 0.1 \mathrm{ml} & 6 \mathrm{M} \mathrm{HCl}-0.06 \mathrm{M} \mathrm{HF} \\ \text { Mo } & 0.25 \mathrm{ml} & 6 \mathrm{M} \mathrm{HNO}_{3}-0.2 \mathrm{M} \mathrm{HF}\end{array}$

and samples were processed following the steps shown in Table 3. This two-column procedure resulted in final purified fractions with $>92 \%$ Zr yields, undetectable Th, U, Ru and REEs, $<2 \%$ of the initial Hf, and $<0.04 \%$ Mo.

The purified $\mathrm{Zr}$ cuts were evaporated to dryness on a hot plate at $130{ }^{\circ} \mathrm{C}$, fluxed overnight in $2 \mathrm{ml}$ of $8 \mathrm{M} \mathrm{HNO}_{3}+15 \mathrm{wt} \%$ $\mathrm{H}_{2} \mathrm{O}_{2}$ mixture to decompose organic residues from the resin, dried down again, taken up in $1 \mathrm{ml}$ of $8 \mathrm{M} \mathrm{HNO}_{3}+14 \mathrm{M} \mathrm{HF}$ to ensure complete re-digestion, slowly evaporated to near dryness, and diluted into $2 \mathrm{ml}$ of $0.59 \mathrm{M} \mathrm{HNO}_{3}+0.28 \mathrm{M} \mathrm{HF}$. A 2.5\% $(50 \mu \mathrm{l})$ aliquot from this solution was taken for $\mathrm{Zr}$ concentration measurement on the MC-ICP-MS and to verify optimal Mo removal. Samples were then diluted to a final $\mathrm{Zr}$ concentration of $60 \mathrm{ng} \mathrm{g}^{-1}$ in $0.59 \mathrm{M} \mathrm{HNO}_{3}+0.28 \mathrm{M} \mathrm{HF}$ for MCICP-MS measurements.

\section{Reagent and procedural blanks}

Reagents used in this study were prepared at UR-LIG using subboiling distillation in dedicated Savillex® DST-1000 units. Reagent blanks determined by isotope dilution were between 2.5 and $3.6 \mathrm{pg} \mathrm{g}^{-1} \mathrm{Zr}$ for the batches of concentrated $\mathrm{HCl}, \mathrm{HF}$ and $\mathrm{HNO}_{3}$ used for this study.

Several total procedural blanks were also measured to determine the level of laboratory contamination introduced by our dissolution and chemical purification methods. Pre-cleaned beakers were loaded with the same volumes of clean acid used for digesting our samples and spiked with ca. $50 \mathrm{ng}$ of total $\mathrm{Zr}$ from our calibrated DS tracer. These blank loads underwent the complete chemical procedure alongside 'unknown' doublespiked zircons, and measurements were performed using the methods outlined below. Procedural blanks were found to be between $c a$. 0.2 and $0.5 \mathrm{ng}$ of $\mathrm{Zr}$, which are three orders of magnitude smaller than the typical $\mathrm{Zr}$ loads of our doublespiked samples ( $600 \mathrm{ng})$ and thus negligible.

\section{Mass spectrometry}

$\mathrm{Zr}$ isotopic measurements were performed using two instruments: (i) a Nu Plasma II MC-ICP-MS using an Aridus II desolvating nebulizer at the Massachusetts Institute of Technology, and (ii) a Thermo Scientific Neptune Plus using an Aridus 3 at the Isotoparium, California Institute of Technology. Measurements were performed in low mass resolution on both instruments. Static configurations were used to monitor masses 90 through 98 (Table 2). All Faraday cups in the Nu Plasma II were fitted with $10^{11} \Omega$ feedback resistors. On the Neptune Plus, all Faraday cups were assigned $10^{11} \Omega$ feedback resistors with the exception of $\mathrm{H} 1\left({ }^{95} \mathrm{Mo}\right)$ and $\mathrm{H} 4\left({ }^{98} \mathrm{Mo}\right)$, which were assigned $10^{12}$ $\Omega$ feedback resistors to improve measurement accuracy for Mo isobaric interference monitoring and corrections. Cup gains are calibrated daily on both instruments.

Solutions were aspired using nebulizers with nominal flow rates of $100 \mu \mathrm{l} \mathrm{min}{ }^{-1}$ in both laboratories. The average 
a) Ln-Spec resin

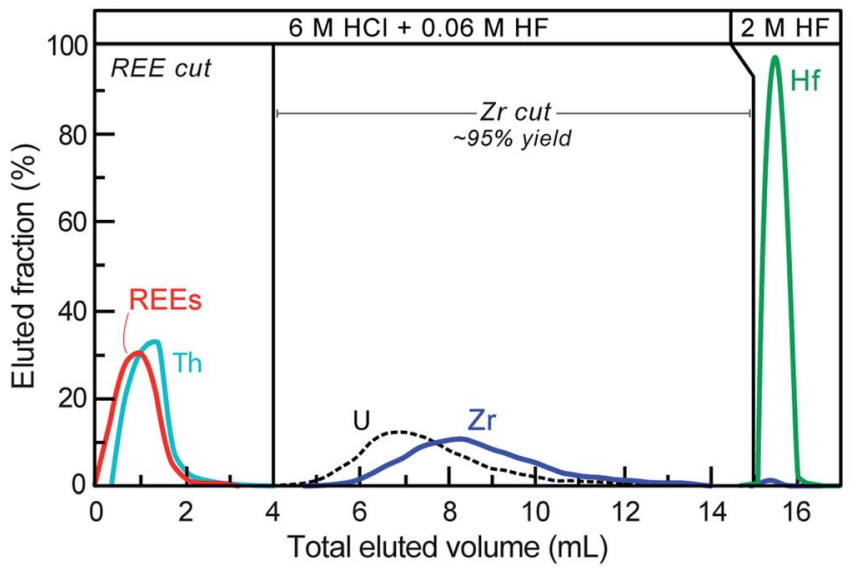

b) AG1-X8 resin

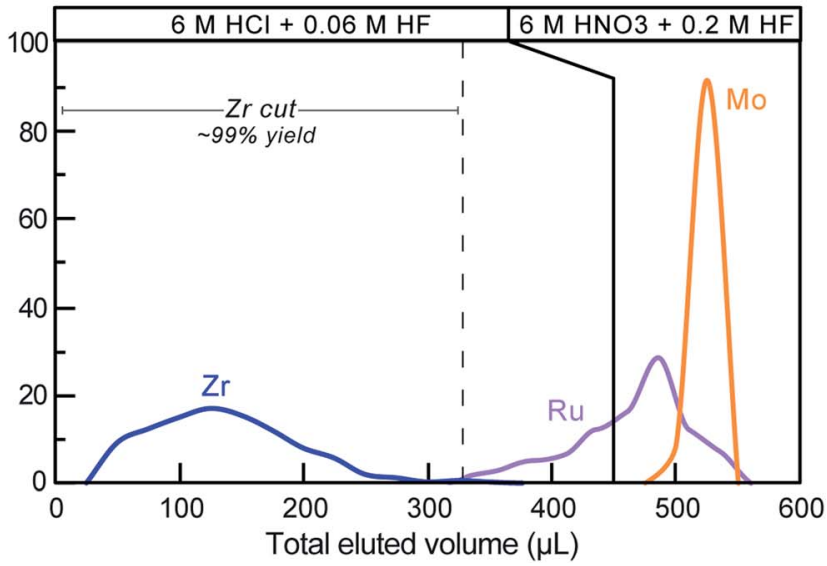

Fig. 3 Elution curves for the two-step ((a): Ln-Spec, (b): AG1-X8) chromatographic purification of Zr from a zircon matrix. Note that $U$ is not released at the molarities used on AG1-X8. If any $\mathrm{Hf}$ is present in the AG1-X8 step, it elutes along with the $\mathrm{Zr}$.

sensitivities were $\sim 450 \mathrm{~V}$ per ppm $\mathrm{Zr}$ on the Nu Plasma II using enhanced sensitivity cones, and $\sim 520 \mathrm{~V}$ per ppm $\mathrm{Zr}$ on the Neptune Plus using regular cones. This resulted in average beam intensities of $8.5 \mathrm{~V}(\mathrm{Nu}$ Plasma II) and 9.2 V (Neptune Plus) on ${ }^{90} \mathrm{Zr}$, the most abundant isotope $(\sim 32 \%)$ in our DSsample mixtures when analyzing $60 \mathrm{ng} \mathrm{g}^{-1}$ (total $\mathrm{Zr}$ ) solutions.

For wet-plasma measurements performed on the Nu Plasma II, sample introduction of $1 \mu \mathrm{g} \mathrm{g}^{-1} \mathrm{Zr}$ solutions using a 100

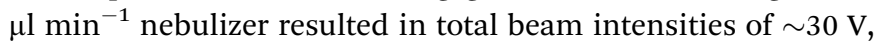
or a sensitivity of $\sim 30 \mathrm{~V}$ per ppm.

Each unknown measurement was bracketed by measurements of the NIST RM8299 Zr iRM, a new Zr isotopic reference material recently prepared in a collaboration between the UR-LIG, the Isotoparium, and the U.S. National Institute of Standards and Technology (NIST). Bracketing standards were spiked at the same level as the samples. Before each measurement, a $60 \mathrm{~s}$ baseline integration was performed while deflecting the ion beam using the ESA. On-peak-zeros (OPZ) were measured using a $50 \mathrm{~s}$ uptake and $20 \mathrm{~s}$ on-peak measurement of clean acid solution from the same batch used to dilute the samples, allowing monitoring of memory effects of the sample introduction system. Sample and bracketing standard measurements consisted of $50 \mathrm{~s}$ of sample uptake, followed by 50 cycles of $4.192 \mathrm{~s}$ (Neptune) or $5 \mathrm{~s}$ (Nu Plasma) integration time each, for a total of $c a$. 210-250 s of static on-peak sample measurement. The sample introduction system was rinsed for $360 \mathrm{~s}$ between samples using $0.59 \mathrm{M} \mathrm{HNO}_{3}+0.56 \mathrm{M} \mathrm{HF}$, before repeating the cycle for the next standard/unknown. Each measurement consumed approximately $750 \mathrm{mg}$ of solution (i.e., $\sim 680 \mu \mathrm{l})$, equivalent to $\sim 45 \mathrm{ng}$ of $\mathrm{Zr}(\sim 25 \mathrm{ng}$ from the sample and $\sim 20 \mathrm{ng}$ from the spike).

Within each sequence, a secondary reference material was measured to monitor mass spectrometer performance and ensure inter-session data accuracy (see details below). The 18 micro-cores from MTUR1 were analyzed three to six times each on both mass spectrometers, in a non-sequential fashion to evaluate the reproducibility of individual measurements and thus accuracy of the isotopic composition determined for each micro-core.

\section{Double-spike data reduction}

After OPZ correction, data reduction of double-spiked data was performed by simultaneously solving a system of non-linear equations of the form:

$$
R_{\text {Meas }}^{i / n}=\left[p R_{\text {Spike }}^{i / n}+(1-p) R_{\text {Std }}^{i / n}\left(M_{i} / M_{n}\right)^{\alpha}\right]\left(M_{i} / M_{n}\right)^{\beta}
$$

where $R_{\text {Meas }}$ is the measured isotopic ratio of the spike-sample mixture, $R_{\text {Std }}$ and $R_{\text {Spike }}$ are the isotopic ratio of the reference standard and DS, respectively, $p$ is the ratio of abundance of the normalizing isotope in the spike over that in the spike-sample mixture, $M_{i}$ is the absolute mass of the isotope of interest, $M_{n}$ is the absolute mass of the normalizing isotope, $\alpha$ is the natural fractionation factor between the sample and the reference standard, and $\beta$ is the instrumental fractionation factor. ${ }^{39-41,52}$ Because there are three unknowns in eqn (2), at least four isotopes need to be measured such that three equations can be inverted simultaneously in order to solve the system.

A key assumption of the double spike approach, which is built into eqn (2), is that the composition of the sample and the standard are mass-dependently related by a fractionation factor $\alpha$ :

$$
R_{\mathrm{sample}}^{i / n}=R_{\mathrm{Std}}^{i / n}\left(M_{i} / M_{n}\right)^{\alpha}
$$

By rearranging eqn (2) and (3), the sample ratios can also be calculated explicitly as the measured ratios stripped from the spike composition and corrected for instrumental mass bias, $\beta$ :

$$
R_{\text {sample }}^{i / n}=\left(R_{\text {Meas }}^{i / n} /\left(M_{i} / M_{n}\right)^{\beta}-p R_{\text {Spike }}^{i / n}\right) /(1-p)
$$

When only 3 ratios are used to solve for $\alpha, \beta$, and $p$, an exact solution always exists, and eqn (3) and (4) will, by construction, yield the exact same results. In such cases, mass-dependency amongst the three ratios used for inversion after DS processing is an outcome imposed by the data treatment assumptions.

Zirconium, however, has 5 stable isotopes, providing 4 ratios that can be used to reduce the data in at least two general ways: (i) using different combinations of 4 isotopes (e.g. ${ }^{90 / 91 / 92 / 96} \mathrm{Zr}$ or 
${ }^{90 / 91 / 94 / 96} \mathrm{Zr}$ ) for exactly solving the system as described above, or (ii) with a minimization approach that uses all 5 isotopes (i.e., 4 ratios). Unlike the exact solving method, when using a 4-ratio minimization approach, eqn (3) and (4) do not necessarily return the same result. The values of $\alpha, \beta$, and $p$ found by the minimization algorithm will return a sample composition, as calculated with eqn (4), that is mass-dependently related to the standard for all four ratios only if the measured ratios are free of mass-independent artifacts: e.g., isotope anomalies, interferences, and/or other systematic biases. The 4-ratio minimization approach therefore comes with a built-in data quality control, which we leverage here.

Data was reduced using a minimization approach implemented in Mathematica ${ }^{\circledR}$, taking into account all ratios (i.e., ${ }^{91 / 90} \mathrm{Zr}$, ${ }^{92 / 90} \mathrm{Zr},{ }^{94 / 90} \mathrm{Zr}$ and ${ }^{96 / 90} \mathrm{Zr}$ ) with different weights being assigned to each based on their associated measurement uncertainty. All reported $\mathrm{Zr}$ isotope ratios are calculated explicitly using eqn (4) to allow any deviations from mass-dependency to be readily identified. For completeness, 'exact' solutions to the system using only 3 isotope ratios were also performed using the ${ }^{91 / 90} \mathrm{Zr},{ }^{94 / 90} \mathrm{Zr}$ and ${ }^{96 /}$ ${ }^{90} \mathrm{Zr}$ ratios (i.e., optimal data reduction recommended by the double spike toolbox $\left.{ }^{39}\right)$. This procedure was done as an internal consistency check and in all instances the exact solving and 4-ratio minimization approaches yielded identical results within uncertainty (see discussion in Results section). The data reported throughout this study correspond to values obtained using the 4-ratio minimization approach for DS inversion.

\section{Primary isotopic reference material and data reporting}

Due to the dearth of previous $\mathrm{Zr}$ stable isotopic investigations, no standards of certified isotopic composition are available. In order to remediate this, a new isotopic standard for $\mathrm{Zr}$ was prepared in collaboration between our group and NIST. A large batch of a concentrated gravimetric Zr solution was prepared at NIST using an ultra-high purity Zr metal rod as starting material, and an aliquot of that solution was used for this investigation (henceforth referred to as $\mathrm{Zr}_{\text {NIST }}$ ). An exhaustive inter-laboratory calibration of the NIST solution (NIST RM8299 Zr iRM) is currently underway and will be reported in a future contribution. Therefore, no values for this standard are reported here to avoid future confusion. It should be noted, however, that the absolute isotopic composition of the $\mathrm{Zr}_{\mathrm{NIST}}$ standard is immaterial for the conclusions of this study as all data reported here are expressed as offsets relative to $\mathrm{Zr}_{\mathrm{NIST}}$. Our results will thus be readily comparable to all future $\mathrm{Zr}$ isotopic investigations using the $\mathrm{Zr}_{\text {NIST }}$ standard once it becomes commercially available.

The isotopic compositions reported here use the $m u(\mu)$ notation, ${ }^{53}$ which represents part-per-million deviations in the $\mathrm{Zr}$ isotopic composition of our samples relative to the $\mathrm{Zr}_{\text {NIST }}$ isotopic standard according to eqn (5):

$$
\mu^{9 x / 90} \mathrm{Zr}=\left[\left({ }^{9 x / 90} \mathrm{Zr}_{\text {sample }} /^{9 x / 90} \mathrm{Zr}_{\text {NIST }}\right)-1\right] \times 10^{6}
$$

where $x$ can be $1,2,4$ or 6 depending on the $\mathrm{Zr}$ isotope considered in the numerator. Sample-standard bracketing was performed by linear interpolation using the bracketing standards measured immediately before and after the unknown solution. For simplicity, only the $\mu^{94 / 90} \mathrm{Zr}$ values are shown in figures, but for completeness and to demonstrate the massdependency of our measurements the $\mu^{91 / 90} \mathrm{Zr}, \mu^{92 / 90} \mathrm{Zr}$ and $\mu^{96 / 90} \mathrm{Zr}$ values obtained after DS inversion are also included in all tables where results are reported (Tables 4 and 5).

While stable isotope studies traditionally report sample compositions in delta $(\delta)$ notation (i.e., isotope-ratio offsets relative to the standard in parts-per-mil), we use here the $\mu$ notation because of: (i) the small degree of variability observed, and (ii) the high level of analytical precision. Conversion to traditional $\delta$ values can be simply done by dividing our reported $\mu$ offsets by $10^{3}$.

For each day of analyses, the dispersion of the standardbracketed standard (2SD) for each isotope ratio was calculated using linear interpolation. Uncertainties for individual sample measurements are reported as the 2SD daily external reproducibility of the standard, rather than the internal precision (i.e., from counting statistics) of each measurement.

\section{Monitoring data accuracy: the need for secondary isotopic reference materials}

Because $\mathrm{Zr}$ stable isotope analyses are still in their infancy, no reference materials with 'known' isotopic composition relative to $\mathrm{Zr}_{\text {NIST }}$ are available. To alleviate this, and to monitor data accuracy during and in-between measurement sessions and instruments, we used an ICP-MS Zr calibration solution obtained from SPEX CertiPrep (Lot\# 21-168ZRM; 'Assurance' grade) that was measured systematically during our sessions. This solution consistently yielded values fractionated by $c a$. -80 ppm per amu relative to $\mathrm{Zr}_{\mathrm{NIST}}$, and can thus become a useful secondary reference material for $\mathrm{Zr}$ stable isotope analysis. A reference $\mu^{94 / 90} \mathrm{Zr}$ value of $-320 \pm 20 \mathrm{ppm}$ (2SD) was determined using 'wet plasma' measurements of a $1 \mu \mathrm{g} \mathrm{g}^{-1}$ solution. Measurements in 'wet plasma' mode were performed to evaluate consistency relative to those obtained subsequent by 'dry plasma' using the Aridus II and 3 desolvating nebulizer inlet systems.

During the analytical sessions in which MUTR1 zircon was analyzed, this SPEX solution was measured approximately 28 times in each laboratory: $\sim 10$ times daily, once every 2 to 3 hours. The results of all individual measurement are reported in Table 4 and $\mu^{94 / 90} \mathrm{Zr}$ values summarized in Fig. 4 . Results obtained using the Nu Plasma II yield a mean $\mu^{94 / 90} \mathrm{Zr}=-319 \pm$ 29 ppm (2SD) and measurements made on the Neptune Plus yield a mean $\mu^{94 / 90} \mathrm{Zr}=-325 \pm 19 \mathrm{ppm}$ (2SD). Mean values obtained using both instruments are in excellent agreement with each other and with the wet plasma value, demonstrating accuracy of all routines and the lack of inter-laboratory bias in our measurements.

Industrial secondary reference materials such as the highpurity SPEX solution introduced here are different from natural secondary reference materials (known as 
Table 4 Zr stable isotope data for 'wet-' and 'dry-plasma' measurements of a SPEX CertiPrep solution

$\mathrm{Zr}$ stable isotope compositions ${ }^{a}$
Wet Plasma reference value, $[\mathrm{Zr}]=1 \mu \mathrm{g} \mathrm{g}^{-1}$

SPEX-Wet $\quad-81 \quad$ (2)

MIT Nu Plasma II, Dry Plasma (Aridus II), $[\mathrm{Zr}]=60 \mathrm{ng} \mathrm{g}^{-1}$

\begin{tabular}{|c|c|c|c|c|c|}
\hline SPEX 1 & -79 & (10) & -173 & (21) & -304 \\
\hline SPEX 2 & -80 & (10) & -178 & (21) & -308 \\
\hline SPEX 3 & -85 & (10) & -170 & (21) & -333 \\
\hline SPEX 4 & -82 & (10) & -161 & (21) & -323 \\
\hline SPEX 5 & -81 & (10) & -160 & (21) & -318 \\
\hline SPEX 6 & -83 & (7) & -165 & (26) & -328 \\
\hline SPEX 7 & -80 & (7) & -159 & (26) & -314 \\
\hline SPEX 8 & -80 & (7) & -164 & (26) & -313 \\
\hline SPEX 9 & -85 & (7) & -172 & (26) & -334 \\
\hline SPEX 10 & -81 & (7) & -163 & (26) & -318 \\
\hline SPEX 11 & -82 & (8) & -169 & (20) & -324 \\
\hline SPEX 12 & -89 & (8) & -185 & (20) & -348 \\
\hline SPEX 13 & -80 & (8) & -168 & (20) & -310 \\
\hline SPEX 14 & -83 & (8) & -165 & (20) & -325 \\
\hline SPEX 15 & -73 & (8) & -162 & (20) & -282 \\
\hline SPEX 16 & -81 & (7) & -163 & (26) & -318 \\
\hline SPEX 17 & -83 & (7) & -159 & (26) & -329 \\
\hline SPEX 18 & -88 & (7) & -167 & (26) & -349 \\
\hline SPEX 19 & -78 & (7) & -150 & (26) & -308 \\
\hline SPEX 20 & -83 & (7) & -159 & (26) & -330 \\
\hline SPEX 21 & -86 & (7) & -174 & (26) & -339 \\
\hline SPEX 22 & -76 & (11) & -150 & (34) & -300 \\
\hline SPEX 23 & -79 & (11) & -172 & (34) & -307 \\
\hline SPEX 24 & -83 & (11) & -160 & (34) & -327 \\
\hline SPEX 25 & -80 & (11) & -161 & (34) & -314 \\
\hline SPEX 26 & -79 & (11) & -161 & (34) & -311 \\
\hline SPEX 27 & -76 & (8) & -148 & (17) & -298 \\
\hline SPEX 28 & -80 & (8) & -144 & (17) & -321 \\
\hline
\end{tabular}

Isotoparium Neptune Plus, Dry Plasma (Aridus 3), $[\mathrm{Zr}]=60 \mathrm{ng} \mathrm{g}^{-1}$

$\begin{array}{lll}\text { SPEX 1 } & -86 & (7) \\ \text { SPEX 2 } & -84 & (7) \\ \text { SPEX 3 } & -82 & (7) \\ \text { SPEX 4 } & -79 & (7) \\ \text { SPEX 5 } & -79 & (7) \\ \text { SPEX 6 } & -85 & (6) \\ \text { SPEX 7 } & -80 & (6) \\ \text { SPEX 8 } & -80 & (6) \\ \text { SPEX 9 } & -84 & (4) \\ \text { SPEX 10 } & -86 & (4) \\ \text { SPEX 11 } & -85 & (7) \\ \text { SPEX 12 } & -84 & (7) \\ \text { SPEX 13 } & -83 & (7) \\ \text { SPEX 14 } & -85 & (4) \\ \text { SPEX 15 } & -81 & (4) \\ \text { SPEX 16 } & -83 & (3) \\ \text { SPEX 17 } & -80 & (4) \\ \text { SPEX 18 } & -79 & (4) \\ \text { SPEX 19 } & -83 & (6) \\ \text { SPEX 20 } & -87 & (7) \\ \text { SPEX 21 } & -80 & (7) \\ \text { SPEX 22 } & -82 & (5) \\ \text { SPEX 23 } & -83 & (5) \\ \text { SPEX 24 } & -81 & (5)\end{array}$

(7) $\quad-169$

(7) -177

(7) $\quad-168$

(7) $\quad-148$

(7) -159

(6) -172

(6) -156

(6) -168

(4) -159

(4) -181

(7) $\quad-163$

(7) $\quad-170$

(7) $\quad-163$

(4) -153

(4) -153

(3) -166

(4) -154

(4) $\quad-169$

(6) -162

(7) $\quad-178$

(7) $\quad-166$

(5) -158

(5) -166

(5) -155

$\begin{array}{ll}(17) & -339 \\ (17) & -328 \\ (17) & -319 \\ (17) & -313 \\ (17) & -311 \\ (15) & -334 \\ (15) & -317 \\ (15) & -312 \\ (27) & -334 \\ (27) & -333 \\ (21) & -337 \\ (21) & -329 \\ (21) & -325 \\ (21) & -339 \\ (21) & -322 \\ (10) & -328 \\ (17) & -315 \\ (17) & -309 \\ (18) & -326 \\ (16) & -340 \\ (16) & -313 \\ (20) & -326 \\ (20) & -325 \\ (20) & -320\end{array}$

(20)

(40) -462

(40) $\quad-469$

(40) -496

(40)

(40)

(29)

(29)

(29)
(29)

(29)
(29)

(33)

(33)

(33)

(33)

(33)

(29)

(29)

(29)

(29)
(29)

(29)
(29)

(41)

(41)

(41)

(41)

(41)

(32)

(32)

\section{$-479$}

$-472$

$-486$

$-465$

$-467$

$-497$

$-474$

$-482$

$-520$

$-466$

$-483$

$-429$

$-474$

$-485$

$-515$

$-454$

$-487$

$-505$

$-445$

$-464$

$-483$

$-467$

$-463$

$-441$

$-466$

(29)

(29)

(29)

$(29)$
(29)

(24)

(24)

(24)

(19)

(19)

(25)

(25)

(25)

(18)

(12)

(19)

(19)

(26)

(30)

(21)

(21)

(21)
-502
-493
-477
-459
-464
-498
-468
-469
-490
-502
-496
-491
-482
-493
-474
-487
-466
-466
-482
-508
-469
-480
-483
-471
Mo interference

${ }^{98} \mathrm{Mo} /{ }^{90} \mathrm{Zr}^{b} \quad \mathrm{Mo} / \mathrm{Zr}^{c}$

$\begin{array}{ll}2.00 \times 10^{-5} & 0.003 \%\end{array}$

$\begin{array}{lll}(56) & 2.18 \times 10^{-5} & 0.003 \% \\ (56) & 2.16 \times 10^{-5} & 0.003 \% \\ (56) & 2.17 \times 10^{-5} & 0.003 \% \\ (56) & 2.02 \times 10^{-5} & 0.003 \% \\ (56) & 1.98 \times 10^{-5} & 0.002 \% \\ (43) & 1.58 \times 10^{-5} & 0.002 \% \\ (43) & 2.00 \times 10^{-5} & 0.002 \% \\ (43) & 2.15 \times 10^{-5} & 0.003 \% \\ (43) & 1.90 \times 10^{-5} & 0.002 \% \\ (43) & 1.72 \times 10^{-5} & 0.002 \% \\ (48) & 2.11 \times 10^{-5} & 0.003 \% \\ (48) & 1.74 \times 10^{-5} & 0.002 \% \\ (48) & 2.12 \times 10^{-5} & 0.003 \% \\ (48) & 2.05 \times 10^{-5} & 0.003 \% \\ (48) & 2.14 \times 10^{-5} & 0.003 \% \\ (43) & 1.72 \times 10^{-5} & 0.002 \% \\ (44) & 1.58 \times 10^{-5} & 0.002 \% \\ (44) & 1.55 \times 10^{-5} & 0.002 \% \\ (44) & 1.69 \times 10^{-5} & 0.002 \% \\ (44) & 1.76 \times 10^{-5} & 0.002 \% \\ (44) & 1.92 \times 10^{-5} & 0.002 \% \\ (64) & 1.91 \times 10^{-5} & 0.002 \% \\ (64) & 2.05 \times 10^{-5} & 0.003 \% \\ (64) & 2.02 \times 10^{-5} & 0.003 \% \\ (64) & 2.29 \times 10^{-5} & 0.003 \% \\ (64) & 1.96 \times 10^{-5} & 0.002 \% \\ (45) & 1.68 \times 10^{-5} & 0.002 \% \\ (45) & 1.91 \times 10^{-5} & 0.002 \%\end{array}$

$2.26 \times 10^{-5}$

$2.15 \times 10^{-5}$

$2.30 \times 10^{-5}$

$2.28 \times 10^{-5}$

$2.26 \times 10^{-5}$

$2.60 \times 10^{-5}$

$2.55 \times 10^{-5}$

$2.59 \times 10^{-5}$

$2.67 \times 10^{-5}$

$2.63 \times 10^{-5}$

$2.65 \times 10^{-5}$

$2.66 \times 10^{-5}$

$2.72 \times 10^{-5}$

$2.79 \times 10^{-5}$

$2.73 \times 10^{-5}$

$2.49 \times 10^{-5}$

$2.47 \times 10^{-5}$

$2.48 \times 10^{-5}$

$2.58 \times 10^{-5}$

$2.60 \times 10^{-5}$

$2.28 \times 10^{-5}$

$2.49 \times 10^{-5}$

$2.30 \times 10^{-5}$

$0.003 \%$

$0.003 \%$

$0.003 \%$

$0.003 \%$

$0.003 \%$

$0.003 \%$

$0.003 \%$

$0.003 \%$

$0.003 \%$

$0.003 \%$

$0.003 \%$

$0.003 \%$

$0.003 \%$

$0.004 \%$

$0.003 \%$

$0.003 \%$

$0.003 \%$

$0.003 \%$

$0.003 \%$

$0.003 \%$

$0.003 \%$

$0.003 \%$

$0.003 \%$

$0.003 \%$ 


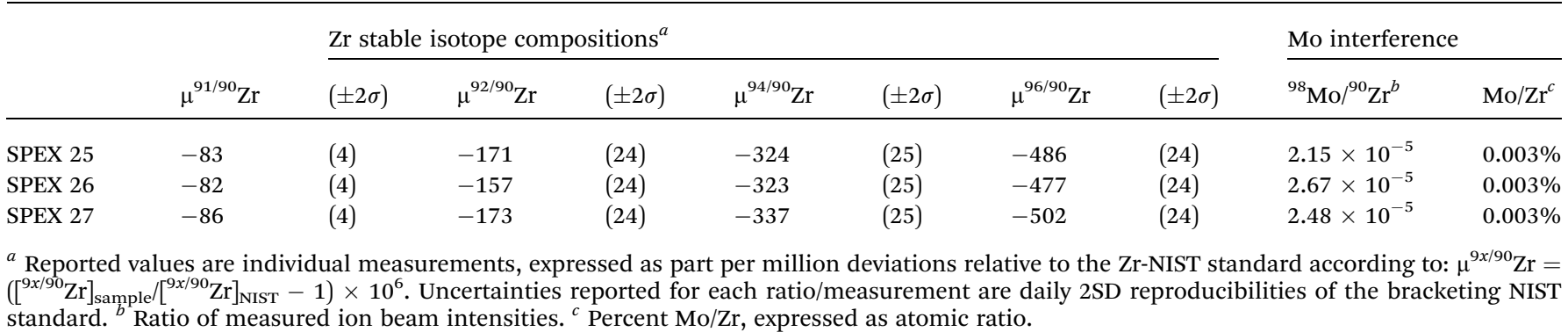

'geostandards') in that they need no additional chemical purification prior to analysis. Measurements of such solutions provide a direct assessment of mass-spectrometer performance, free from potential biases introduced by the chromatographic purification required by natural samples.

Natural 'geostandard' results, on the other hand, provide an assessment for the reproducibility of the complete analytical protocol, being sensitive to biases in sample preparation, chemical purification and mass spectrometry. Industrial secondary reference materials are thus not a replacement for natural 'geostandards', but rather a complement that can be used to isolate mass spectrometry (and/or data acquisition and processing) bias, and to monitor mass spectrometer performance within and in-between analytical sessions.

Aliquots of the SPEX stock solution used in this study can be obtained from M. Ibañez-Mejia and/or F. L. H. Tissot upon request.

\section{Mo isobaric interferences}

Due to the multiple isobaric interferences that Mo isotopes have on $\mathrm{Zr}$ (Table 2), evaluating the effects that residual Mo in purified sample solutions have on the accuracy of the results is paramount. To address this, a doping test was performed in which variable amounts of natural Mo ranging from $c a .3 \times$ $10^{-5}(0.003 \%$ atomic $\mathrm{Mo} / \mathrm{Zr})$ to $c a .1 \times 10^{-2}(1 \%)$ were added to aliquots of a double-spiked $\mathrm{Zr}_{\text {NIST }}$ standard solution. Doped solutions were analyzed using the Neptune Plus at Caltech, bracketed by measurements of the Mo-free standard batch from which all doped solutions were derived.

Results of Mo doping tests are shown in Fig. 5. Isobaric interferences on the ${ }^{92} \mathrm{Zr},{ }^{94} \mathrm{Zr}$ and ${ }^{96} \mathrm{Zr}$ beams were corrected according to the general relationship:

$$
\begin{aligned}
&{ }^{9 x} \mathrm{Zr}_{\text {Corrected }}={ }^{9 x}(\mathrm{Zr}+\mathrm{Mo})_{\text {Meas }}-{ }^{98} \mathrm{Mo}_{\text {Meas }} {\left[\left(\frac{{ }^{9 x} \mathrm{Mo}}{{ }^{98} \mathrm{Mo}}\right)_{\text {Ref }}\right.} \\
&\left.\times\left(\frac{\mathbf{M}_{9 x}}{\mathbf{M}_{98}}\right)^{\beta \mathrm{Mo}}\right]
\end{aligned}
$$

where 'Meas' are measured beam intensities, 'Ref' is a reference natural Mo isotope ratio $\left(\mathrm{after}^{40}\right), \beta \mathrm{Mo}$ is the instrumental mass fractionation factor for $\mathrm{Mo}$, and $\mathbf{M}_{9 x}$ are the exact masses of the respective Mo isotopes.

Due to the low beam intensities measured for the un-interfered ${ }^{95} \mathrm{Mo},{ }^{97} \mathrm{Mo}$ and ${ }^{98} \mathrm{Mo}$ masses in doping experiments and chemically purified solutions, accurate determination of withinrun $\beta \mathrm{Mo}$ is not possible. Three potential ways for addressing this issue are illustrated in Fig. 5a, namely: (i) no correction for Mo instrumental mass fractionation is applied for isobaric interference corrections (i.e., $\beta \mathrm{Mo}=0$; blue symbols); (ii) Mo instrumental mass fractionation is approximated from the mean $\mathrm{Zr}$ mass fractionation determined from bracketing standards (i.e., $\beta \mathrm{Mo}=\beta \mathrm{Zr}$; green symbols); (iii) Mo instrumental mass fractionation is approximated by optimization, using the mean $\mathrm{Zr}$ fractionation determined from bracketing standards multiplied by a conversion factor $(x)$ that minimizes the offset between the Mo-doped solutions and the Mo-free bracketing standards (i.e., $\beta \mathrm{Mo}=x \times \beta \mathrm{Zr}$; white symbols).

The first approach, $\beta \mathrm{Mo}=0$, clearly makes an unsatisfactory assumption, because Mo will in fact be affected by instrumental mass fractionation. The inaccuracy of this is confirmed by the large negative offsets in $\mu^{94 / 90} \mathrm{Zr}$ that arise when $\mathrm{Mo} / \mathrm{Zr}$ ratios are near or above $2 \times 10^{-4}$ (Fig. 5a). Assuming $\beta \mathrm{Mo}=\beta \mathrm{Zr}$ results in more accurate corrections, and resolvable deviations only occur when $\mathrm{Mo} / \mathrm{Zr}$ ratios exceed $c a .5 \times 10^{-3}$. Nevertheless, at large interference ratios this approach over-corrects Mo interference (i.e., $\mu^{94 / 90} \mathrm{Zr}$ offsets becomes resolvably positive), indicating that the effective $\beta$ Mo during measurements is smaller than $\beta \mathrm{Zr}$. Lastly, using the optimization approach $(\beta \mathrm{Mo}=x \times \beta \mathrm{Zr})$, we find that a conversion factor $x=0.9$ results in isobaric interference corrections that are accurate even for our highest doping ratio of $c a .1 \% \mathrm{Mo} / \mathrm{Zr}$. We note that such percent-level differences in the magnitude of $\beta$ even for elements of similar mass are common, as are, for example, typically observed when correcting $\mathrm{Hf}$ isotopic ratios for $\mathrm{Yb}$ and/or Lu isobaric interference (e.g., (ref. 54-57)).

Fig. $5 \mathrm{~b}$ shows the offset of all ratios (i.e., ${ }^{91 / 90} \mathrm{Zr},{ }^{92 / 90} \mathrm{Zr},{ }^{94 / 90} \mathrm{Zr}$, ${ }^{96 / 90} \mathrm{Zr}$ ) as obtained after correction using our optimization approach (i.e., $\beta \mathrm{Mo}=0.9 \times \beta \mathrm{Zr}$ ). This demonstrates that the optimization method could potentially be used to accurately correct large offsets caused by Mo isobaric interference in all $\mathrm{Zr}$ masses, even when within-run Mo beams are too low for allowing direct determination of $\beta$ Mo. Nevertheless, even the simplest $\beta \mathrm{Mo}=\beta \mathrm{Zr}$ model yields indistinguishable results from the optimization model within the Mo/Zr range measured in our chemically purified zircon solutions (grey shaded range in Fig. 5). Therefore, selection of one correction method over the other has no impact on the accuracy of our results. For simplicity, the data reported here were calculated assuming $\beta \mathrm{Mo}=\beta \mathrm{Zr}$. 
Table 5 Zr stable isotope data for MTUR1 zircon megacryst and 91500 zircon reference material

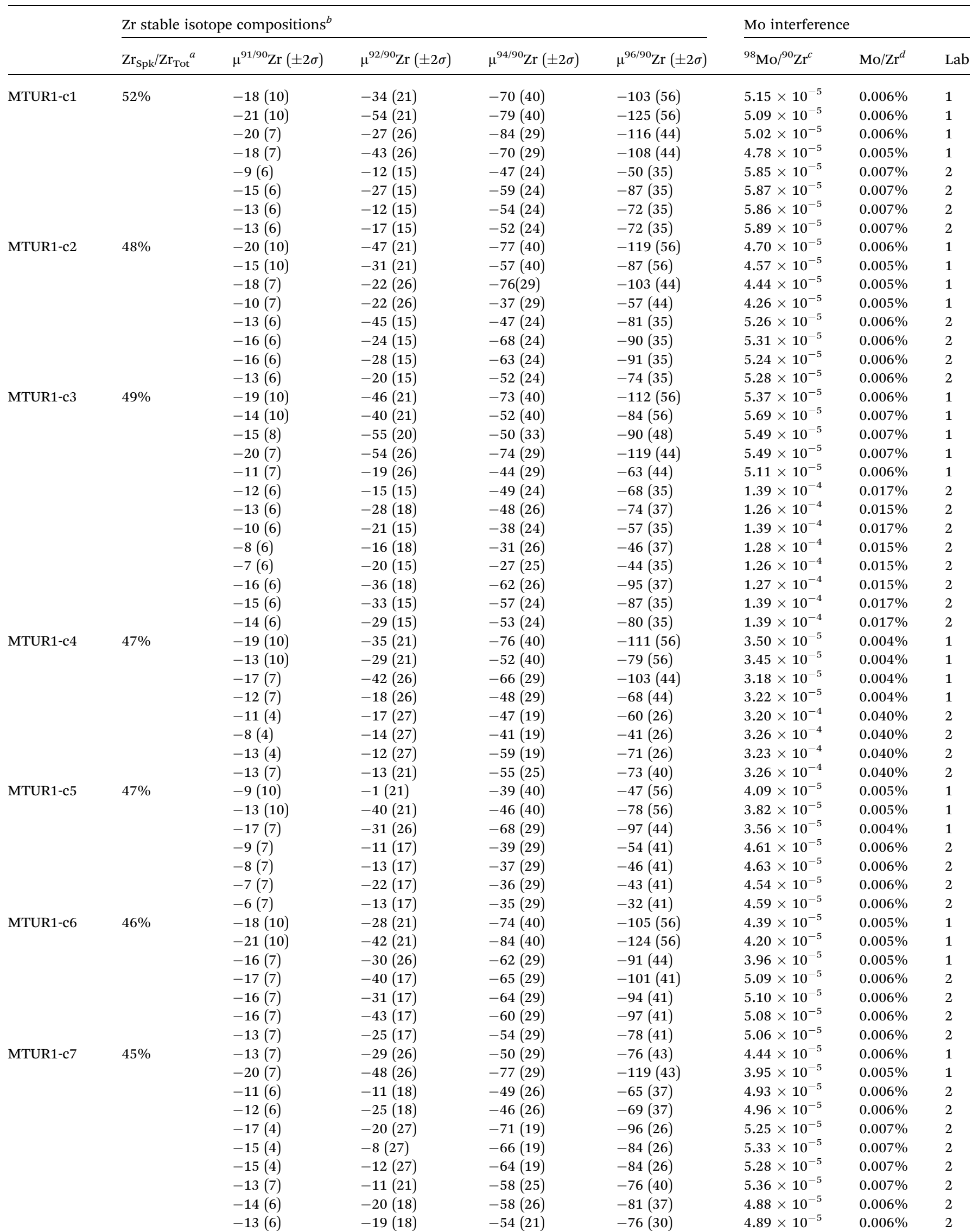


Table 5 (Contd.)

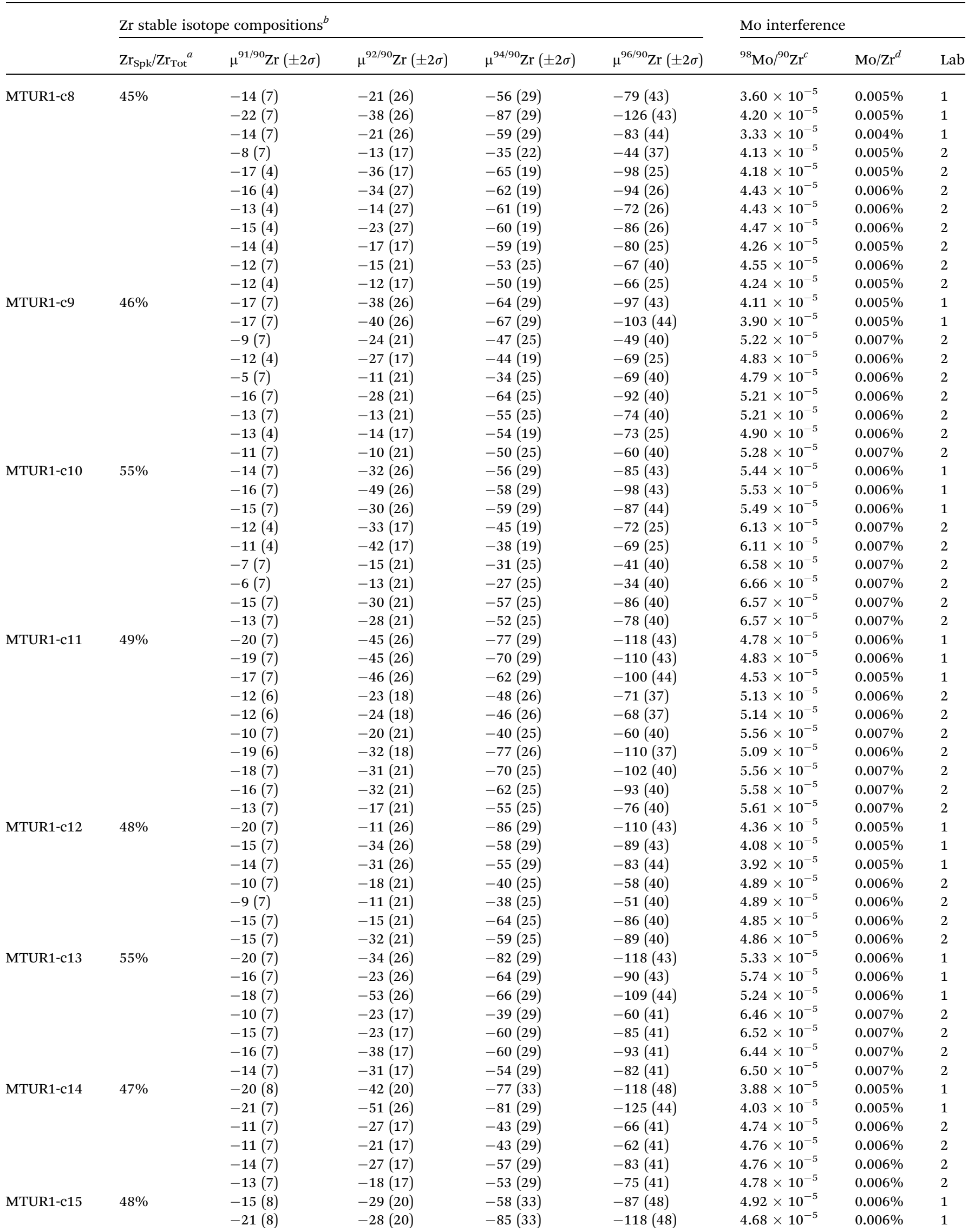


Table 5 (Contd.)

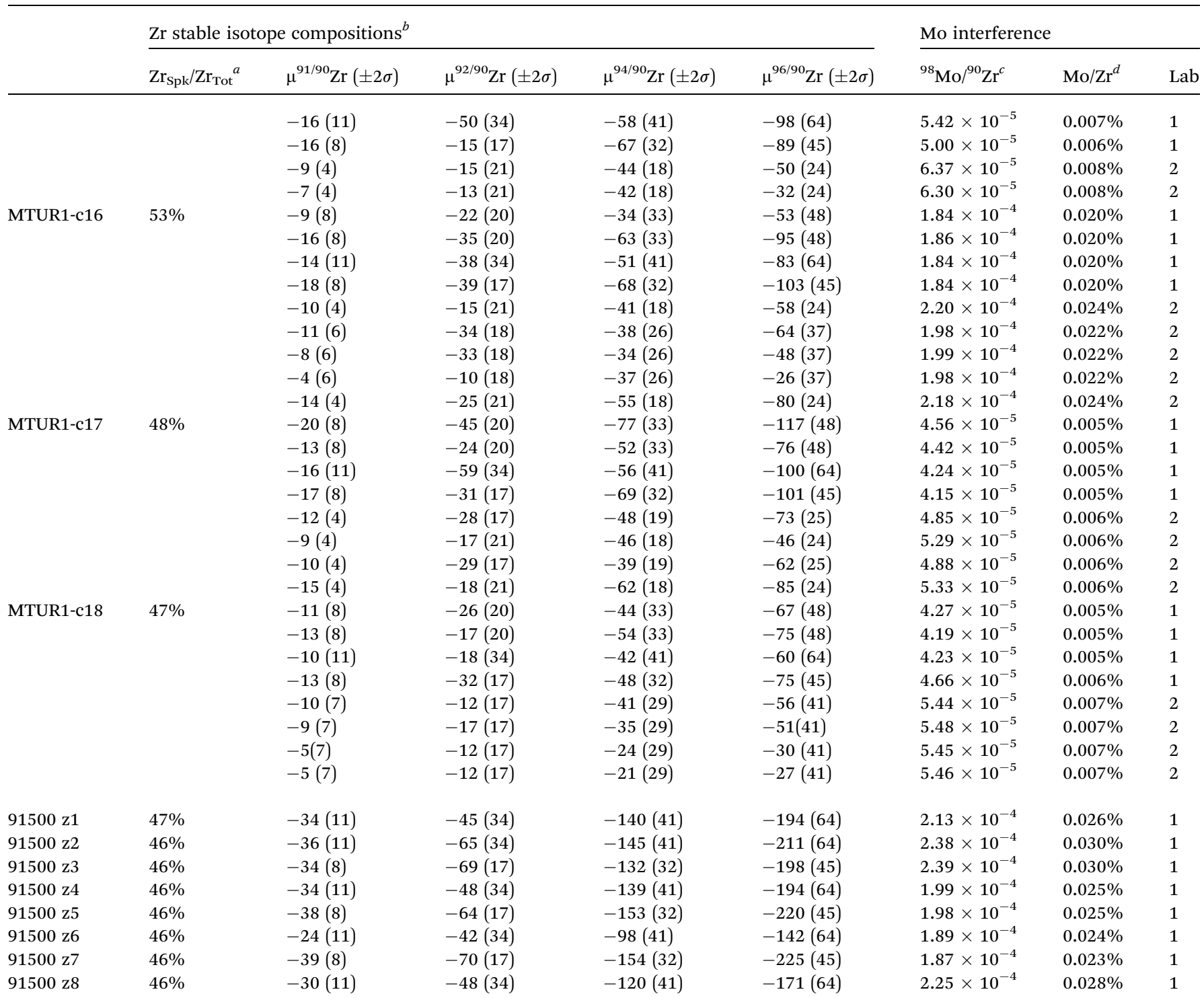

${ }^{a}$ Fraction of Zr (by mass) from double spike in the spike-sample mixture, calculated by isotope dilution. ${ }^{b}$ Reported values are individual measurements for each fraction, expressed as part per million deviations relative to the Zr-NIST standard according to: $\mu^{9 x / 90} \mathrm{Zr}=\left(\left[{ }^{9 x / 90} \mathrm{Zr}\right]_{\text {sample }} /\right.$ $\left.\left[{ }^{9 x / 90} \mathrm{Zr}\right]_{\mathrm{NIST}}-1\right) \times 10^{6}$. Uncertainties reported for each ratio/measurement are daily 2SD reproducibilities of the bracketing NIST standard.

${ }^{c}$ Ratio of measured ion beam intensities. ${ }^{d}$ Percent Mo/Zr, expressed as atomic ratio. Lab: $1=$ Nu Plasma II at MIT; $2=$ Neptune Plus at Caltech's Isotoparium.

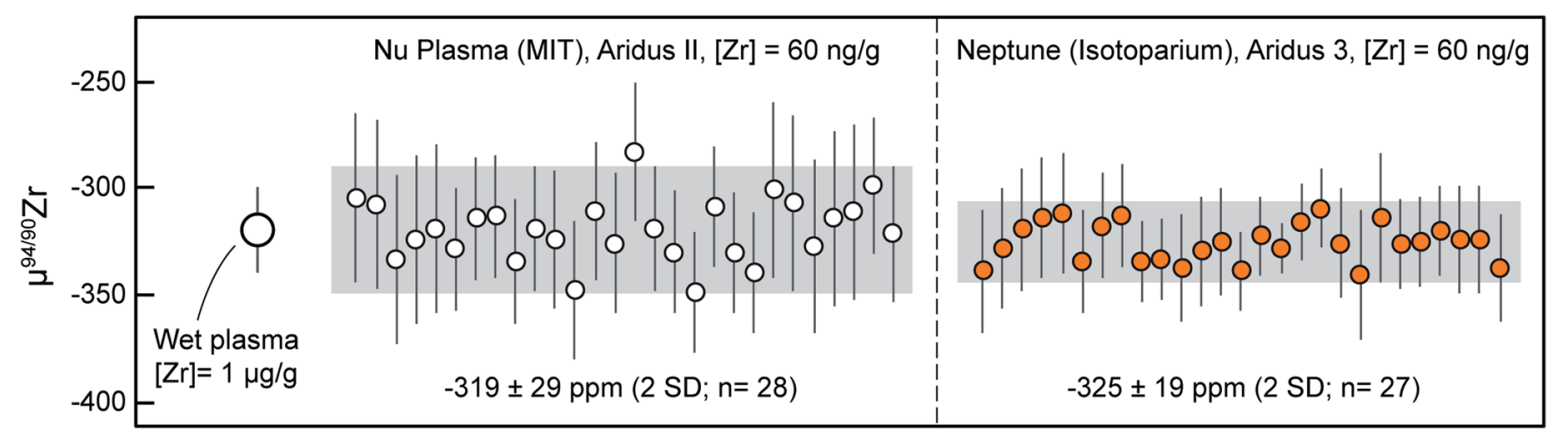

Fig. 4 Measurements of the SPEX secondary reference material performed during this study using a Nu Plasma II (at MIT) and a Thermo Neptune Plus (at the Isotoparium, Caltech). All dry plasma measurements were performed within the same analytical sessions as the Mud Tank and 91500 zircons. Data point uncertainties are the 2SD of bracketing standards and gray shaded regions represent the 2SD of the data. 

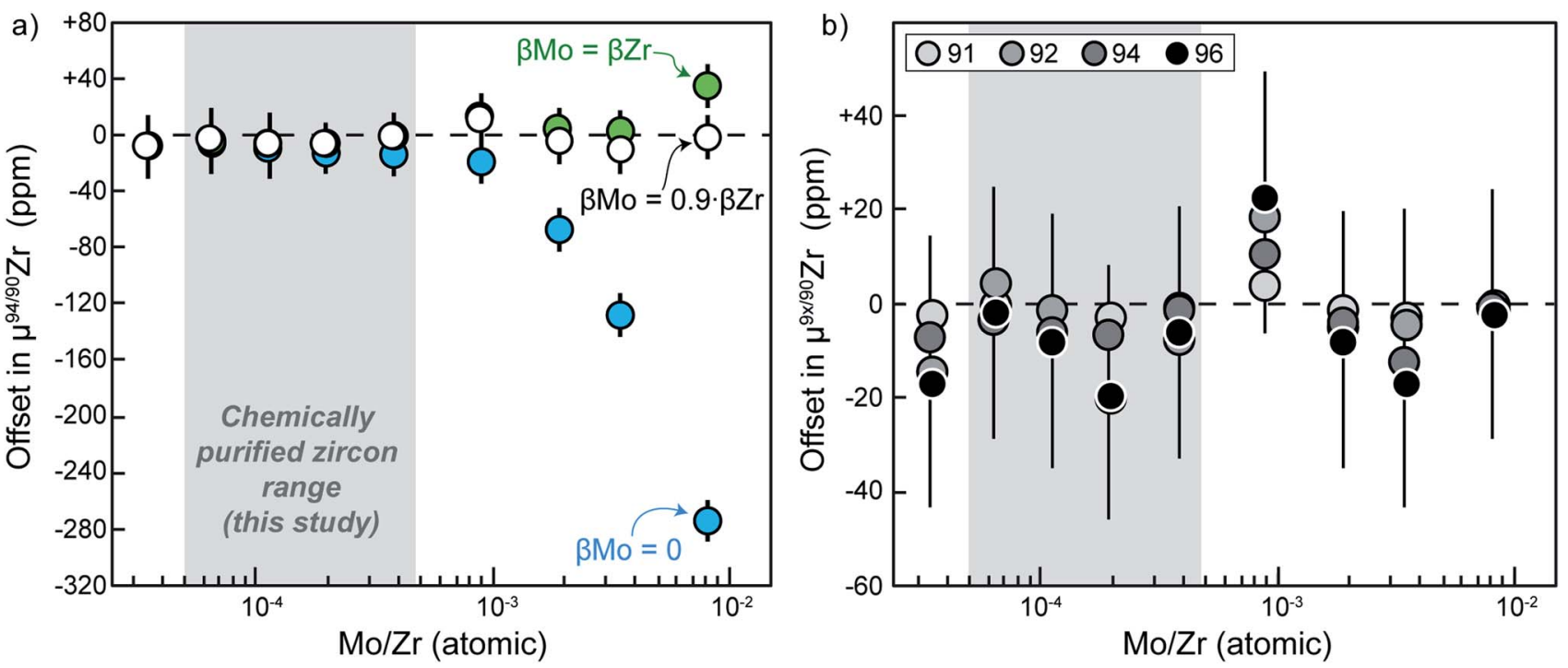

Fig. 5 Results of Mo doping tests in which variable amounts of natural Mo were added to a double-spiked Zr $r_{\text {NIST }}$ solution to quantify the offsets in $\mu^{9 \times / 90} \mathrm{Zr}$ induced by residual Mo isobaric interferences. (a) Offset in $\mu^{94 / 90} \mathrm{Zr}$ vs. Mo/Zr atomic ratio in the solution. As the Zr and Mo instrumental mass biases $(\beta)$ are not necessarily identical, the influence of the choice of $\beta$ Mo is shown: $\beta \mathrm{Mo}=0$ (blue), $\beta \mathrm{Mo}=\beta \mathrm{Zr}$ (green), and $\beta \mathrm{Mo}=0.9 \beta \mathrm{Zr}$ (white). (b) Offset in $\mu^{9 \times / 90} \mathrm{Zr}$ vs. Mo/Zr atomic ratio using the best value of $\beta \mathrm{Mo}=0.9 \beta \mathrm{Zr}$. Data point uncertainties are the $2 \mathrm{SD}$ of bracketing standards.

\section{Results}

The 18 micro-cores from MTUR1 were analyzed three to six times each on both mass spectrometers, and the results (Table 5 ) indicate that this megacryst is isotopically homogeneous within the uncertainties of our method (Fig. 6). All MTUR1 replicates yield a mean $\mu^{94 / 90} \mathrm{Zr}=-55 \pm 28 \mathrm{ppm}(2 \mathrm{SD}, n=151)$. As mentioned previously, data reduction was performed in two ways for all measurements: (i) by exactly constraining the system described in eqn (2) using only the ${ }^{91 / 90} \mathrm{Zr}$, ${ }^{94 / 90} \mathrm{Zr}$ and ${ }^{96 / 90} \mathrm{Zr}$ ratios; and (ii) by over-constraining the system using a minimization approach that takes into account all measured ratios (i.e., ${ }^{91 / 90} \mathrm{Zr},{ }^{92 / 90} \mathrm{Zr},{ }^{94 / 90} \mathrm{Zr}$ and ${ }^{96 / 90} \mathrm{Zr}$ ). Fig. 6c illustrates a comparison of these two reduction approaches, where " $\Delta$ inv." represents the difference in $\mu^{94 / 90} \mathrm{Zr}$ for all replicates between the two data reduction methods. Differences are always smaller than $\pm 6 \mathrm{ppm}$, or $\pm 1.5 \mathrm{ppm}$ per amu, and thus negligible compared to our average uncertainties ( $\sim 7$ ppm per amu). Values shown in all figures and Tables 4 and 5 correspond to results obtained using the 4-ratio minimization approach.

Results from all 91500 fragments analyzed here (Table 5) are also identical within uncertainty (Fig. 7) and yield a mean $\mu^{94 / 90} \mathrm{Zr}=-135 \pm 37 \mathrm{ppm}(2 \mathrm{SD}, n=8)$. Although we have no spatial control of where within the 91500 zircon megacryst the fragments analyzed here were derived, the fact that all results agree within uncertainty suggests that this megacryst is likely compositionally homogeneous for $\mathrm{Zr}$ isotopes.

\section{Discussion}

\section{Accuracy of Zr stable isotope results}

In order to assess the accuracy of the MTUR1 Zr isotope results described above, two key aspects were carefully evaluated: (1) the effect of residual isobaric interferences, and (2) the mass dependency of the determined variations after DS inversion.

Potential offsets due to residual Mo isobaric interferences can be assessed using the doping experiment shown in Fig. 5 and the $\mathrm{Mo} / \mathrm{Zr}$ ratios determined in our samples during MCICP-MS measurement (Table 5). The $\mathrm{Mo} / \mathrm{Zr}$ ratios of our chemically purified solutions are all below $4 \times 10^{-4}$, within the range where no resolvable offsets are observed in our doping test. Furthermore, the lack of a systematic dependence between $\mu^{94 / 90} \mathrm{Zr}$ and $\mathrm{Mo} / \mathrm{Zr}$ in the MTUR1 dataset (Fig. 8) bolsters the conclusion that the low residual Mo present in our samples after chemical purification do not impact the accuracy of our results outside the reported uncertainties.

Determining stable isotope variations in natural samples using a DS relies on a key assumption: the differences in composition between a sample and the standard must be massdependent in nature, at least for the masses being used for DS inversion $^{34,38,39,58}$ (see eqn (2)). If after performing the DS inversion with more than 3 isotope ratios the relative offsets of the spike-stripped ratios used to solve the system do not scale proportionally with mass difference, then this could indicate that: (i) the measurements may be affected by residual spectral interferences; (ii) there may be mass-independent (e.g., radiogenic) sources of variability in at least one of the isotopes used for inversion; or (iii) the mass fractionation law used for inversion is not correct.

The means and 2SD of all $\mathrm{Zr}$ isotopic ratios $(n=151)$ determined in the MTUR1 micro-cores are $\mu^{91 / 90} \mathrm{Zr}=-14 \pm$ $8 \mathrm{ppm}, \mu^{92 / 90} \mathrm{Zr}=-27 \pm 24 \mathrm{ppm}, \mu^{94 / 90} \mathrm{Zr}=-55 \pm 28 \mathrm{ppm}$ and $\mu^{96 / 90} \mathrm{Zr}=-80 \pm 46 \mathrm{ppm}$. When scaled relative to mass difference, these translate to offsets of $-14 \pm 8,-13 \pm 12,-14 \pm 7$ and $-13 \pm 8$ ppm per amu, respectively, indicating mass 
a)

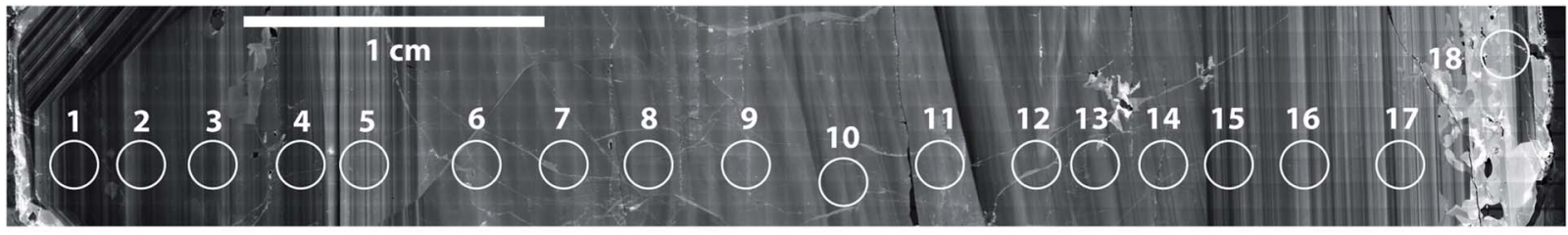

b)

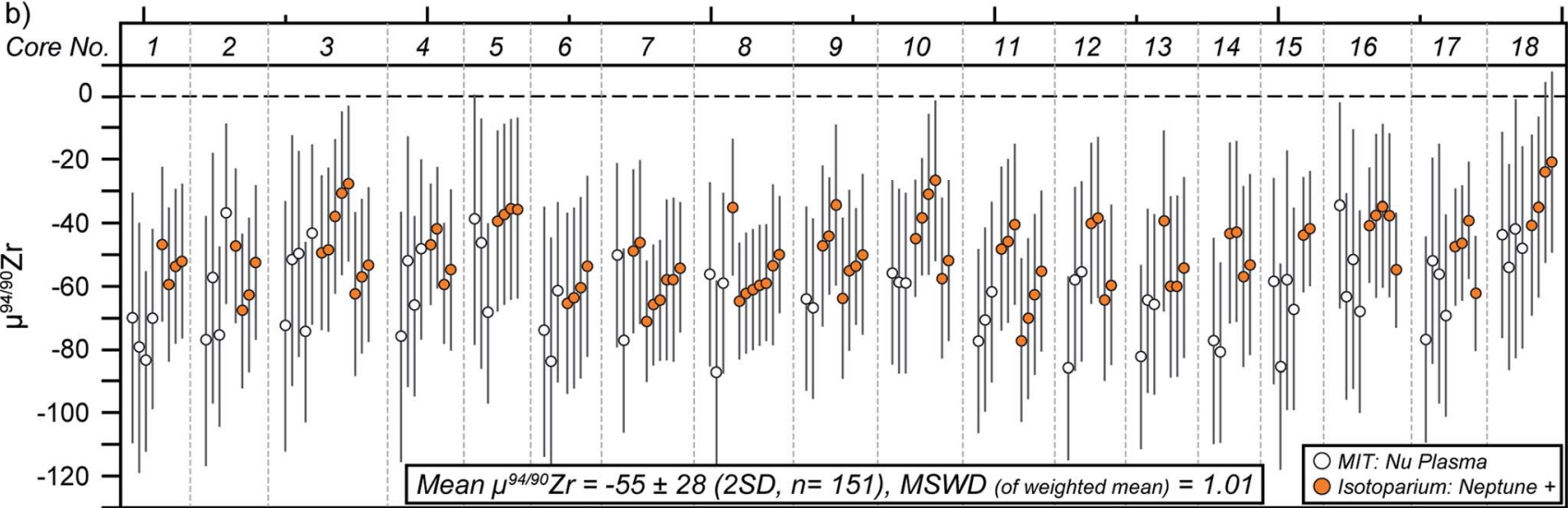

c)

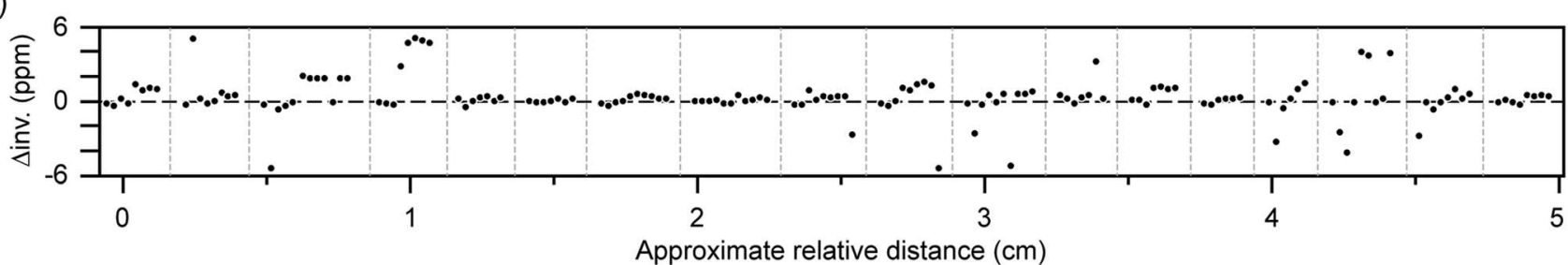

Fig. 6 Mud Tank zircon results. (a) Cathodoluminescence traverse along the MTUR1 zircon region where micro-cores were sampled; (b) $\mu^{94 / 90} \mathrm{Zr}$ vs. relative distance (in $\mathrm{cm}$ ) from micro-core no. 1 . All 151 replicates from the 18 micro-cores yield a mean $\mu^{94 / 90} \mathrm{Zr}=-55 \pm 28 \mathrm{ppm}$. The MSWD of a weighted mean of all data is 1.01. Data point uncertainties are the 2SD of bracketing standards (see text); (c) difference in $\mu^{94 / 90} \mathrm{Zr}$ (in $\mathrm{ppm})$ for all replicates between the two data reduction methods described in the text, calculated as $\Delta$ inv. $=\left(\mu^{94 / 90} \mathrm{Zr}\right)_{\mathrm{ExactSolving}}-$ $\left(\mu^{94 / 90} \mathrm{Zr}\right)_{4 \text { RatioMinimization. }}$

dependency within uncertainty. In the case of 91500 , the means and $2 \mathrm{SD}$ of all ratios $(n=8)$ are $\mu^{91 / 90} \mathrm{Zr}=-34 \pm 9 \mathrm{ppm}, \mu^{92 / 90} \mathrm{Zr}$ $=-56 \pm 23 \mathrm{ppm}, \mu^{94 / 90} \mathrm{Zr}=-135 \pm 37 \mathrm{ppm}$ and $\mu^{96 / 90} \mathrm{Zr}=$ $-194 \pm 54 \mathrm{ppm}$, which translate to $-34 \pm 9,-28 \pm 12,-34 \pm 9$ and $-32 \pm 9 \mathrm{ppm}$ per amu offsets, respectively. The fact that all

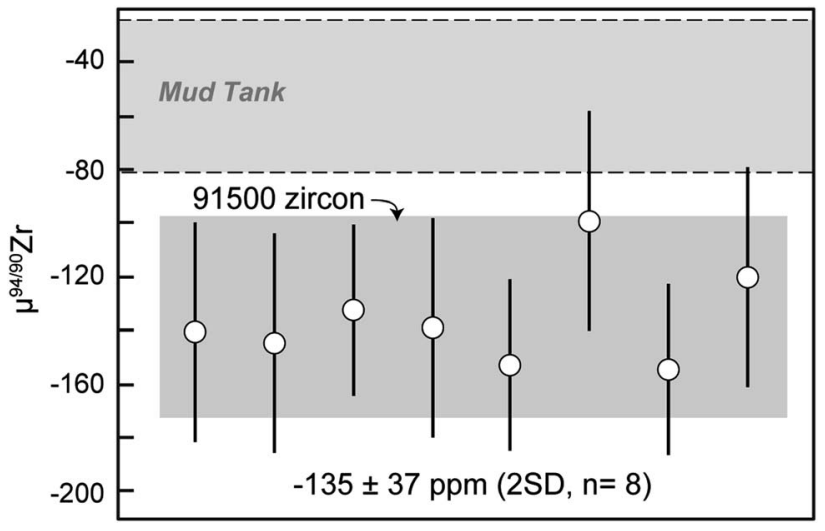

Fig. 791500 zircon $\mu^{94 / 90} Z$ r results. Data point uncertainties are the 2SD of bracketing standards and gray shaded regions represent the 2SD of the data. ratios are mass-dependently related to the standard, clearly demonstrates that: (1) the measured variations are indeed mass-dependent in nature and can be accurately resolved using our method; (2) the use of the double spike technique is warranted, and (3) no unidentified interferences are causing systematic biases to the reported ratios.

\section{Precision of $\mathrm{Zr}$ stable isotope analysis of zircon}

Multiple factors are known to contribute to the uncertainty of isotopic measurements conducted by MC-ICP-MS, such as counting statistics, thermal (i.e., Johnson-Nyquist) noise, instrumental mass-bias instability and isobaric interferences, amongst others. ${ }^{38,41,59,60}$ In the case where samples are accurately spiked, the mass spectrometer is stable, and instrumental mass bias and isobaric interferences are properly accounted for, measurement uncertainties should closely approach theoretical expectations. Fig. 9a shows the proportion of Zr DS in the spikesample mixture (calculated by isotope dilution) for all measured MTUR1 micro-cores. A comparison with the optimal spike : sample ratio (see Fig. 1a) demonstrates that all solutions were appropriately spiked: i.e., within $\pm 10 \%$ of the optimal spiking value where negligible uncertainty amplification ( $c a$. $0.2 \mathrm{ppm}$ per amu) is introduced. 


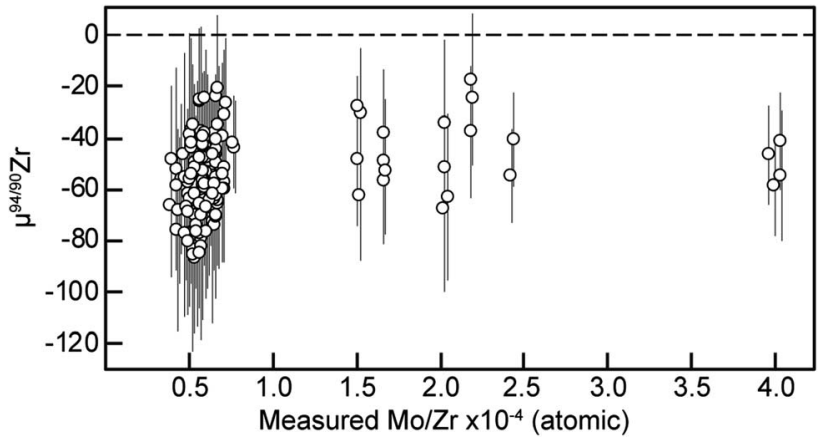

Fig. $8 \mu^{94 / 90} \mathrm{Zr}$ vs. Mo/Zr (atom\%) of all replicates measured from the 18 MTUR1 zircon micro-cores. Data point uncertainties are the 2SD of bracketing standards.

Fig. 9b compares the theoretically predicted uncertainty (expressed as standard error) of individual $\mu^{94 / 90} \mathrm{Zr}$ determinations (see Fig. 1b) with the internal precision of all MTUR1 measurements. Although the single-measurement precision approaches theoretical expectations from detector thermalnoise modelling, the distribution of uncertainty indicates that there must be additional sources of instability contributing to the final uncertainties (e.g., sample introduction instabilities or small secular deviations from exponential mass bias). Therefore, the precision of individual $\mu^{94 / 90} \mathrm{Zr}$ determinations may be better approximated using the reproducibility (standard deviation) of standard-bracketed-standards, herein called $\sigma_{\text {Massspec }}$, rather than from internal counting statistics alone.

Dauphas et al. ${ }^{59}$ proposed a scheme for determining the precision of stable Fe isotope measurements, by combining the reproducibility of the primary reference material within a given analytical session with the reproducibility of a secondary reference material that has undergone chemical purification. Using their approach, the total uncertainty of the analytical protocol $\left(\sigma_{\text {Data }}\right)$ for an initially homogeneous material can be estimated from the sum of the variance associated with mass spectrometer instability $\left(\sigma_{\text {Massspec }}{ }^{2}\right)$ and other sources of variance associated with the procedure $\left(\sigma_{\text {Unknown }}{ }^{2}\right)$ according to the relationship: $\sigma_{\text {Data }}{ }^{2}={\sigma_{\text {MassSpec }}}^{2}+\sigma_{\text {Unknown }}{ }^{2}$. Beginning with the $\sigma_{\text {Massspec }}$ term only, if the MSWD for a weighted mean of replicate measurements of a standard material is sufficiently close to unity (i.e., within the $95 \%$ confidence interval at a given number of degrees of freedom ${ }^{61,62}$ ), this indicates that analytical uncertainties are properly estimated and are well explained by mass spectrometer instability. On the other hand, if the calculated MSWD is significantly above 1 (i.e., outside $95 \%$ confidence), then the results call for a non-zero $\sigma_{\text {Unknown }}$ that can be empirically estimated by adjusting this parameter until the MSWD statistic is brought down to unity.

Using the uncertainties reported for all dry-plasma measurements of the SPEX solution (Table 4), the calculated MSWD of the $\mu^{94 / 90} \mathrm{Zr}$ weighted mean is 0.85 for measurements made with the Nu Plasma II, and 0.64 for measurements performed on the Neptune Plus. In both cases, the MSWD falls within the $95 \%$ confidence interval when the number of degrees of freedom $(\nu$ ) equals 27 (i.e., MSWD between 0.48 and 1.62).
These results indicate that the analytical uncertainties assigned to each replicate $\left(\sigma_{\text {Massspec }}\right)$ are adequate for explaining the scatter observed in repeated measurement of a pure secondary reference material that has not undergone chemical purification after DS addition and equilibration.

To assess whether the assigned analytical uncertainties can adequately explain the scatter of a natural material analyzed multiple times after undergoing chemical purification, we use the MTUR1 zircon results. In the Results section, we argued that the MTUR1 zircon crystal is homogeneous within uncertainty of our measurements. Indeed, the MSWD of a weighted mean $\mu^{94 /}$ ${ }^{90} \mathrm{Zr}$ using all MTUR1 data yields a value of 1.01, which is within the $95 \%$ confidence interval for $\nu=150$ (i.e., from $c a .0 .78$ to 1.27). This observation again indicates that the uncertainties assigned to each replicate adequately explain their scatter around the mean, and therefore that $\sigma_{\text {Unknown }}$ for the $\mathrm{Zr}$ isotope analysis of zircon using our method is statistically insignificant. This result shows that our double-spike method effectively accounts for mass fractionation during chemical purification and drifts in instrumental mass-bias, which can be significant when determining stable isotope compositions of unspiked solutions relying solely on standard-sample bracketing..$^{59}$

In summary, the reproducibility of the $n=151$ MTUR1 zircon measurements reported here is in excellent agreement with the reproducibility of the SPEX reference solution, and both are well explained by the external reproducibility (2SD) of standard-bracketed-standards. This indicates that short-term fluctuations in the linearity of instrumental drift appear to be the dominant source of uncertainty for the $\mathrm{Zr}$ isotopic measurements (i.e., $\sigma_{\text {Massspec }} \gg \sigma_{\text {Unknown }}$ ). Therefore, no propagation of uncertainties beyond those determined from the external reproducibility of the standard $\left(\sigma_{\text {Massspec }}\right)$ within each run are necessary. The method described here hence yields $\mathrm{Zr}$ isotope results that are both accurate and precise to within $c a$. $\pm 7 \mathrm{ppm}$ per amu, or $\pm 28 \mathrm{ppm}$ for $\mu^{94 / 90} \mathrm{Zr}$ (at $95 \%$ confidence), at the individual measurement level.

\section{Influence of sample preparation on $\mathrm{Zr}$ isotope analysis}

Mass-dependent $\mathrm{Zr}$ isotope variability was first reported by Akram and Schönbächler ${ }^{18}$ (see their supplementary materials), who found pure (synthetic) solutions and three natural samples to yield ${ }^{91} \mathrm{Zr} /{ }^{90} \mathrm{Zr}$ offsets between $-0.4 \%$ and $+0.3 \%$ relative to an in-house standard. Because these results plot along a massdependent fractionation line in ${ }^{91} \mathrm{Zr} /{ }^{90} \mathrm{Zr} v$ s. ${ }^{96} \mathrm{Zr} /{ }^{90} \mathrm{Zr}$ space it is clear the variations are mass-dependent in origin. Nevertheless, the natural sample data were obtained from unspiked solutions that had undergone chemical purification with variable yields, and thus the authors were unable to ascertain whether the observed mass-dependent variations were in fact natural in origin or an artifact of chemical separation..$^{18}$ Although the effects that different chemical purification schemes have in fractionating $\mathrm{Zr}$ isotopes remain to be explored in greater detail, the potential of sample preparation for introducing biases in $\mathrm{Zr}$ isotope data is non-negligible.

Potential biases introduced by different analytical protocols can be better evaluated by comparing results obtained using 

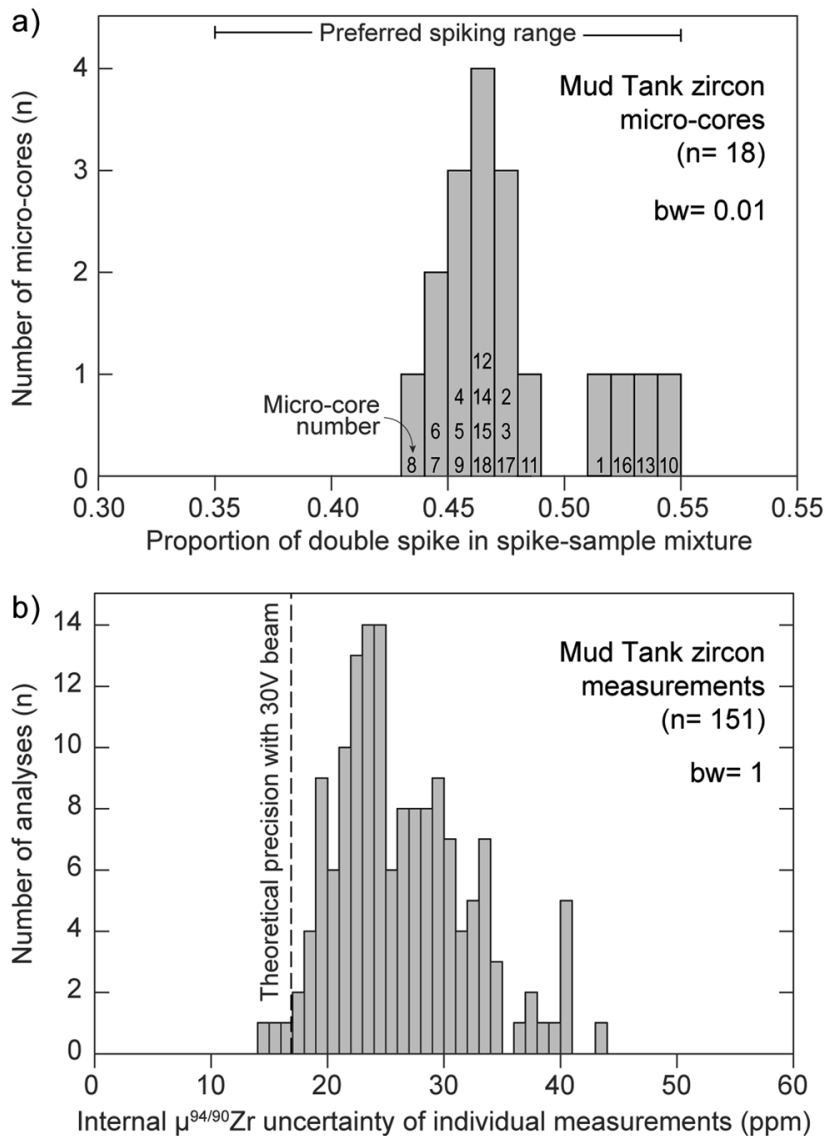

Fig. 9 (a) Proportion of double-spike in the spike-sample mix for all measured MTUR1 micro-cores, determined by isotope dilution. See Fig. 1a for definition of 'preferred spiking range'. Bin width (bw) $=0.01$. (b) Histogram of internal measurement uncertainty, expressed as 2 standard error, of all MTUR1 measurements. Vertical dashed line represents the theoretical precision limit from our spike optimization (see Fig. 1b). Bin width (bw) $=1$.

a DS. While this work is the first to report an in-depth examination of Mud Tank and 91500 zircon, a recent study by Zhang et $a .^{22}$ quoted unpublished $\mathrm{Zr}$ isotope data for these two localities. Both our data and that of Zhang et al. ${ }^{22}$ were produced using a ${ }^{91} \mathrm{Zr}-{ }^{96} \mathrm{Zr}$ DS (independently prepared and calibrated), and state-of-the-art MC-ICPMS instruments. In contrast to our method, however, Zhang et al. used the method of Inglis et al. ${ }^{20}$ in which zircon samples are analyzed without any chemical purification. Furthermore, because normalization was done relative to in-house standards (i.e., IPGP-Zr and GJ-1 zircon), comparison of absolute values is not yet possible.

Taken at face value, the $\mu^{94 / 90} \mathrm{Zr}$ offset between Mud Tank and $91500\left(\mu^{94 / 90} \operatorname{Zr}_{\text {(MudTank) }}-\mu^{94 / 90} \operatorname{Zr}_{(91500)}\right)$ obtained in this study, $80 \pm 65 \mathrm{ppm}$ (2SD), is in good agreement with the value of $100 \pm 110 \mathrm{ppm}$ (2SD) reported by Zhang et al. ${ }^{22}$ To first-order, this suggests that the lack of chemical purification did not result in significant biases in the Zhang et al. ${ }^{22}$ results. We note, however, that the limited $\mathrm{Zr}$ isotope data from zircon available to date and the twice lower precision of the Zhang et al. ${ }^{22}$ data, is insufficient to completely rule out the presence of systematic biases between methods that analyze chemically purified $v s$. non-purified zircon solutions.

\section{No $\mathrm{Zr}$ isotope fractionation in carbonatite systems by zircon crystallization}

Zircon crystallization from a melt has been posited as a driver of $\mathrm{Zr}$ isotope fractionation in silicate magmatic systems, ${ }^{\mathbf{2 1 , 2 3}}$ but discrepancies remain both in the magnitude and direction of the induced variability. While a study in bulk-rock samples from the Hekla volcano inferred zircon to be isotopically light relative to co-existing melt, ${ }^{21}$ a detailed study of zircon and baddeleyite from a closed igneous system in the Duluth Complex concluded that these solids are isotopically heavy relative to the melt from which they precipitated. ${ }^{23}$ In carbonatite systems, the question of whether $\mathrm{Zr}$ isotope fractionation occurs at all remains entirely unconstrained.

If zircon crystallization indeed drives $\mathrm{Zr}$ isotope fractionation via a Rayleigh-type mechanism as previously suggested, ${ }^{21,23}$ then individual zircon crystals growing from a magma would record the changing composition of the liquid as concurrent crystallization and isotopic fractionation take place. To illustrate this, Fig. 10a shows the melt and solid compositional evolution that would be expected from closedsystem Rayleigh fractionation of a liquid as a function of the $\mathrm{Zr}$ fraction removed $(f),{ }^{63}$ using the $\alpha_{\text {sol-liq }}=1.00106$ (or $\Delta^{94 / 90} \mathrm{Zr}_{\text {sol-liq }} \approx+1.06 \%$ o inferred by Ibañez-Mejia and Tissot $^{23}$ as an example. As $f$ increases, the removal of isotopically 'heavy' zircon would drive the liquid towards a complementary 'light' composition, and this change would be recorded by the instantaneous solid composition forming from the liquid at each subsequent step.

Fig. 10b shows a transformation of the instantaneous solid composition of a Rayleigh fractionation model to radial coordinates, assuming: (i) a spherical geometry of $5 \mathrm{~cm}$ diameter (i.e., long-axis dimension of MTUR1); and (ii) that the internal zoning represents growth-integration from $f \approx 0$ at the core, to $f$ $\approx 1$ at the rim. The different curves shown in Fig. 10b represent the different intra-crystalline $\mu^{94 / 90} \mathrm{Zr}$ zonation patterns that would result from various fractionation coefficients between solid and liquid (expressed as $\Delta^{94 / 90} \mathrm{Zr}$ ). As shown in Fig. 6, the MTUR1 megacryst exhibits no resolvable internal variability, which suggests a $\Delta^{94 / 90} \mathrm{Zr} \approx 0$ (within uncertainty) given the calculations shown in Fig. $10 \mathrm{~b}$.

An alternative possibility to explain the lack of internal isotopic zonation in the MTUR1 megacryst is sub-solidus re-equilibration after crystallization. Under this scenario, initial zonation in the megacryst could have been subsequently erased by thermally activated diffusion. Although no experimental or empirical data for $\mathrm{Zr}$ diffusion in zircon are currently available, the relationship between pre-exponential factor for diffusion $\left(D_{0}\right)$ and ionic radius of tetravalent species in zircon ${ }^{64}$ can be used to approximate $\mathrm{Zr}^{4+}$ diffusivity to $\log D_{0} \approx 2.67 \mathrm{~m}^{2} \mathrm{~s}^{-1}$. Assuming a $190 \mathrm{kcal} \mathrm{mol}^{-1}$ activation energy for diffusion, which is typical of tetravalent cations in zircon, ${ }^{64}$ the effective diffusion distance $(2 \sqrt{ } D t)$ for $\mathrm{Zr}$ in zircon can be estimated as a function of time and temperature. ${ }^{65}$ At $650{ }^{\circ} \mathrm{C}$, which is the maximum estimated temperature of emplacement for 
(a)

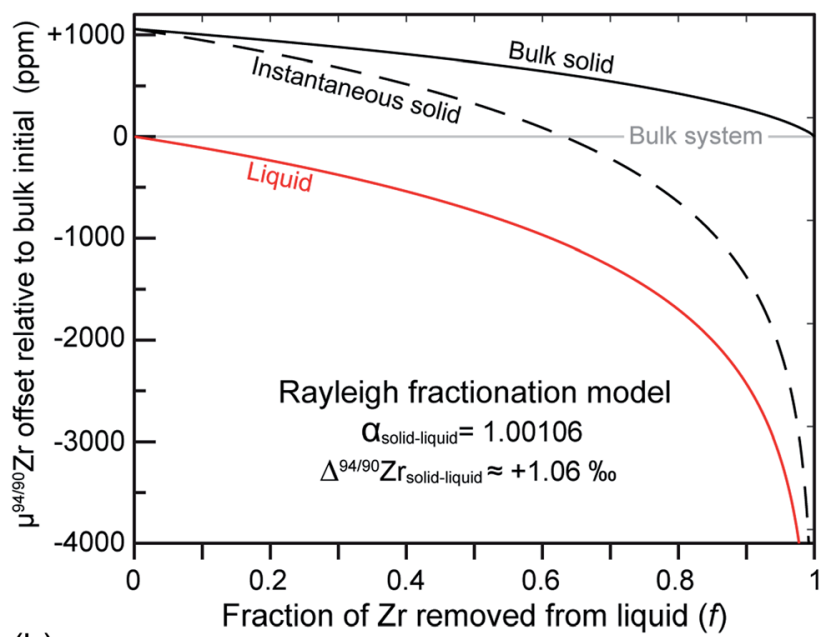

(b)

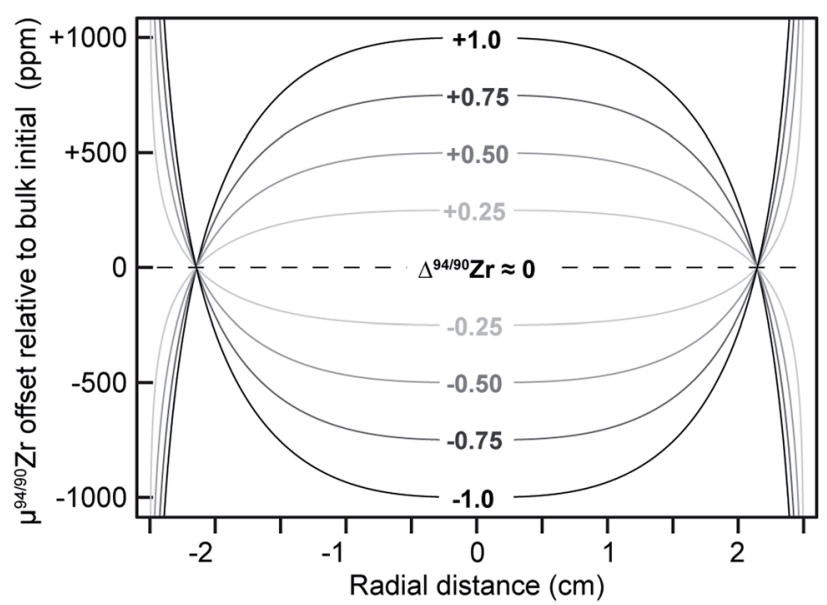

Fig. 10 Illustration of how Rayleigh-type $\mathrm{Zr}$ isotopic fractionation of a magma, as driven by zircon crystallization, would result in intracrystalline isotopic zonation of the solid. (a) Example Rayleigh fractionation diagram showing how the $\mathrm{Zr}$ isotopic composition $\left(\mu^{94 / 90} \mathrm{Zr}\right.$ ) of the liquid and instantaneous solid change as a function of the fraction of $Z r$ removed from the liquid $(f)$. Plot was calculated using an $\alpha_{\text {solid-liquid }}=1.00106$ (or $\Delta^{94 / 90} \mathrm{Zr} \approx+1.06 \%$; after lbañez-Mejia and Tissot ${ }^{23}$ ) for illustration. (b) Diagram showing how different magnitudes of $\alpha_{\text {solid-liquid }}$ (expressed as $\Delta^{94 / 90} \mathrm{Zr}$, for simplicity) translate into different intra-crystalline $\mu^{94 / 90} \mathrm{Zr}$ zonation topologies. Calculations were made assuming a spherical geometry of $5 \mathrm{~cm}$ in diameter (i.e., long-axis dimensions of the MTUR1 megacryst) growing from $f \approx 0$ at the core to $f \approx 1$ at the rim.

the Mud Tank carbonatite, ${ }^{43}$ the effective diffusion distance of $\mathrm{Zr}$ for a heating event of $10 \mathrm{Myr}$ duration is estimated to be on the order of $2 \times 10^{-8} \mu \mathrm{m}$ (i.e., twelve orders of magnitude shorter than the long axis of the studied megacryst). Even if this crystal was held at $1500{ }^{\circ} \mathrm{C}$ for $10 \mathrm{Myr}$, the effective diffusion distance estimated for $\mathrm{Zr}$ would be $c a$. $1.5 \mathrm{~mm}$, which is still negligible relative to the length of the profile shown in Fig. 6 . Therefore, the possibility that the isotopic homogeneity observed in MTUR1 reflects a sub-solidus re-equilibration feature is highly unlikely.

The observations made above indicate that the exceedingly slow diffusivity of tetravalent species in zircon likely prevent efficient diffusive re-equilibration of $\mathrm{Zr}$ within this mineral (and with the surrounding melt) over typical magmatic temperatures and timescales. Thus, the lack of resolvable isotopic zonation at the $\pm 7 \mathrm{ppm}$ per amu level in the MTUR1 megacryst is most compatible with the conclusion that zircon crystallization in carbonatite magmas is not a main driver of $\mathrm{Zr}$ stable isotope fractionation.

\section{MTUR1, a natural zircon reference material for $\mathrm{Zr}$ isotope analysis}

Zircon megacrysts from the Mud Tank locality are widely used as a natural 'geostandards' for U-Pb geochronology, trace element analyses and $\mathrm{Lu}-\mathrm{Hf}$ isotope geochemistry by spatially resolved methods ${ }^{32}$ (e.g., SIMS and LA-ICP-MS). Our results demonstrate that the MTUR1 megacryst studied here is isotopically homogenous for $\mathrm{Zr}$ isotopes, therefore providing an opportunity to use it as a natural reference material for $\mathrm{Zr}$ isotopic analyses. Small aliquots of this crystal can be requested by other laboratories interested in conducting $\mathrm{Zr}$ stable isotope measurements in zircon by solution ( \pm double spike) methods, and rigorously evaluate potential inter-laboratory biases at high precision.

Recent studies have also explored the potential of obtaining moderate-precision $\mathrm{Zr}$ stable isotope compositions of zircon via micro-beam methods such as LA-MC-ICP-MS ${ }^{22}$ and HyperionSIMS. ${ }^{66}$ Because the accuracy of isotopic compositions determined by micro-beam methods is, in general, significantly improved by the use of matrix-matched reference materials, ${ }^{56,67}$ a demonstrably homogeneous zircon for $\mathrm{Zr}$ stable isotopes is a valuable resource for these approaches. Furthermore, because Mud Tank zircon crystals are well-known for having low accumulated radiation damage ${ }^{68,69}$ due to their generally low $\mathrm{U}$ concentrations, ${ }^{32}$ a homogeneous megacryst from this locality is particularly well suited as a primary reference material for micro-beam $\mathrm{Zr}$ isotope analysis as it will minimize potential matrix effects introduced by sampling of a radiation-damaged structure.

Fragments of the MTUR1 megacryst are available for distribution to interested laboratories and can be obtained by contacting M. Ibañez-Mejia and/or F. L. H. Tissot.

\section{Recommendations for reporting $\mathrm{Zr}$ stable isotope data}

Although Zr stable isotope analyses are still in their infancy, it is clear that the production of highly precise and accurate data requires careful considerations of the impact of interferences and other analytical artifacts stemming from sample processing. To enhance data transparency and evaluation of data accuracy, we propose that future $\mathrm{Zr}$ studies adopt some simple recommendations:

(1) Given the large impact of even small amounts of Mo and isobaric interference correction strategies (see Fig. 5), Mo/Zr ratios for each sample fraction should be measured, reported (e.g., Tables 4 and 5) and isobaric interference corrections performed. Because MC-ICP-MS instruments allow simultaneous monitoring of at least ${ }^{95} \mathrm{Mo},{ }^{97} \mathrm{Mo}$, and/or ${ }^{98} \mathrm{Mo}$ along with all $\mathrm{Zr}$ masses of interest, this critical measurement is easy to perform and does not add additional time or difficulty to the process. 
(2) Because of the potential that isobaric and/or molecular interferences and matrix effects have for introducing nonsystematic offsets to stable isotope results, ${ }^{\mathbf{4 1 , 5 2 , 5 9 , 6 0}}$ particularly when multiple isotopic ratios must be considered simultaneously in DS inversions, the mass-dependency of the data should be documented. For example, in the case of $\mathrm{Zr}$ this can be done by reporting the $\delta$ (or $\varepsilon, \mu$, etc.) values of all $\mathrm{Zr}$ isotopic ratios (e.g., Tables 4 and 5) and/or by using a 4-ratio minimization as described here. When measurements are performed using a double-spike, a lack of mass-dependency, if present, would be indicative of an inaccurate result. Reporting all isotope ratios will thus allow verification of the mass-dependent nature of the isotopic effects, which is a requirement for accurate double-spike inversion and data reduction (e.g., (ref. 34, 35, 38, 39, 41 and 70)).

(3) Inter-comparisons of $\mathrm{Zr}$ isotope data would be significantly enhanced by the use of a common standard. The $\mathrm{Zr}_{\mathrm{NIST}}$ standard described here is currently undergoing rigorous interlaboratory calibration as a community-wide effort. This standard was designed and produced using NIST and community ${ }^{53}$ guidelines to meet the stringent needs of a system where singledigit ppm precisions need to be achieved. We note that this is the first effort of its kind for $\mathrm{Zr}$ isotopes, and suggest this standard be adopted by all laboratories performing $\mathrm{Zr}$ isotopic measurement (mass-dependent and -independent) once it becomes commercially available. In the meantime, aliquots of the standard solution can be obtained upon request to the authors.

(4) Results for at least one secondary reference material should be reported, to further support the accuracy of the results. These can be results from either a pure (industrial) reference material, a 'geostandard' that has undergone chemical purification, or ideally both. Consistent reporting of secondary reference material data will provide the means to continuously re-assess the accuracy and reproducibility of $\mathrm{Zr}$ stable isotope measurements as the technique matures, and will enable robust inter-laboratory comparisons needed to evaluate/resolve bias.

\section{Conclusions}

We have shown that: (1) the Mud Tank zircon megacryst studied here, MTUR1, has a homogenous $\mathrm{Zr}$ stable isotope composition $\left(\mu^{94 / 90} \mathrm{Zr}=-55 \pm 28 \mathrm{ppm}\right)$, indicating that zircon crystallization is unlikely to be a driver of $\mathrm{Zr}$ stable isotopic fractionation in carbonatitic magmas; (2) our analytical method for $\mathrm{Zr}$ isotope analysis of zircon is precise and accurate to within \pm 7 ppm per amu (at 2SD) for individual measurements consuming only $\sim 25 \mathrm{ng}$ of sample $\mathrm{Zr}$, which opens new avenues for probing the isotopic composition of zircon and other minerals at high analytical and volume resolution (e.g., single-silicate-crystal scale); and (3) the MTUR1 zircon megacryst provides a demonstrably homogenous reference material for $\mathrm{Zr}$ isotopic determinations in zircon. This new natural reference material directly bridges the gap between microbeam and solution-based ( \pm double spike) methods, by allowing results obtained using both approaches to be directly linked to the new $\mathrm{Zr}_{\mathrm{NIST}}$ isotopic standard currently under development.

The contrast between the results presented here and studies of silicate igneous systems ${ }^{21,23}$ suggests that differences in $\mathrm{Zr}$ speciation may result in contrasting $\mathrm{Zr}$ isotope fractionation during crystallization of zircon from carbonatite vs. silicate liquids. Therefore, additional ab initio, experimental and spectroscopic investigations of $\mathrm{Zr}$ speciation in magmas of variable compositions will be key to further understand the drivers of $\mathrm{Zr}$ stable isotope fractionation during magmatic fractional crystallization.

\section{Conflicts of interest}

There are no conflicts to declare.

\section{Acknowledgements}

David McGee is thanked for access to the MIT Nu Plasma II, and Joel DesOrmeau for the careful and time-consuming SEM-CL imaging of MTUR1 at U. Nevada in Reno. Matthew Bown, Chaofeng $\mathrm{Li}$ and an anonymous reviewer are thanked for constructive comments that helped improve the final version of this manuscript. This research was supported by a Stephen Pollock Undergraduate Research Grant awarded by the NE section of the Geological Society of America (to HT), NSF-EAR grants 1823748 (to MIM) and 1824002 (to FT) and start-up funds to MIM provided by University of Rochester and to FT provided by Caltech.

\section{Notes and references}

1 S. Weyer, C. Münker, M. Rehkämper and K. Mezger, Chem. Geol., 2002, 187, 295-313.

2 C. Münker, G. Wörner, G. Yogodzinski and T. Churikova, Earth Planet. Sci. Lett., 2004, 224, 275-293.

3 J. A. Pfänder, C. Münker, A. Stracke and K. Mezger, Earth Planet. Sci. Lett., 2007, 254, 158-172.

4 P. B. Kelemen, K. Johnson, R. J. Kinzler and A. J. Irving, Nature, 1990, 345, 521-524.

5 L. Lowery Claiborne, C. F. Miller, B. A. Walker, J. L. Wooden, F. K. Mazdab and F. Bea, Mineral. Mag., 2006, 70, 517-543.

6 A. R. Chakhmouradian, Chem. Geol., 2006, 235, 138-160.

7 Q. Xie, R. Kerrich and J. Fan, Geochim. Cosmochim. Acta, 1993, 57, 4111-4118.

8 K. David, P. Schiano and C. J. Allègre, Earth Planet. Sci. Lett., 2000, 178, 285-301.

9 J. F. Minster and L. Ricard, Int. J. Mass Spectrom. Ion Phys., 1981, 37, 259-272.

10 J. F. Minster and C. J. Allègre, Geochim. Cosmochim. Acta, 1982, 46, 565-573.

11 C. Sanloup, J. Blichert-Toft, P. Télouk, P. Gillet and F. Albarède, Earth Planet. Sci. Lett., 2000, 184, 75-81.

12 C. Münker, S. Weyer, K. Mezger, M. Rehkämper, F. Wombacher and A. Bischoff, Science, 2000, 289, 15381542 . 
13 Q. Z. Yin, S. B. Jacobsen, W. F. McDonough, I. Horn, M. I. Petaev and J. Zipfel, Astrophys. J., 2000, 536, L49-L53.

14 M. Schönbächler, M. Rehkämper, A. N. Halliday, D.-C. Lee, M. Bourot-Denise, B. Zanda, B. Hattendorf and D. Günther, Science, 2002, 295, 1705-1708.

15 M. Schönbächler, M. Rehkämper, M. A. Fehr, A. N. Halliday, B. Hattendorf and D. Günther, Geochim. Cosmochim. Acta, 2005, 69, 5113-5122.

16 M. Schönbächler, D.-C. Lee, M. Rehkämper, A. N. Halliday, B. Hattendorf and D. Günther, Geochim. Cosmochim. Acta, 2005, 69, 775-785.

17 W. Akram, M. Schönbächler, S. Bisterzo and R. Gallino, Geochim. Cosmochim. Acta, 2015, 1-46.

18 W. Akram and M. Schönbächler, Earth Planet. Sci. Lett., 2016, 449, 302-310.

19 T. Iizuka, Y.-J. Lai, W. Akram, Y. Amelin and M. Schönbächler, Earth Planet. Sci. Lett., 2016, 439, 172-181.

20 E. C. Inglis, J. B. Creech, Z. Deng and F. Moynier, Chem. Geol., 2018, 493, 544-552.

21 E. C. Inglis, F. Moynier, J. Creech, Z. Deng, J. M. D. Day, F.-Z. Teng, M. Bizzarro, M. Jackson and P. Savage, Geochim. Cosmochim. Acta, 2019, 250, 311-323.

22 W. Zhang, Z. Wang, F. Moynier, E. Inglis, S. Tian, M. Li, Y. Liu and Z. Hu, J. Anal. At. Spectrom., 2019, 34, 1800-1809.

23 M. Ibañez-Mejia and F. L. H. Tissot, Sci. Adv., 2019, 5, eaax8648.

24 L. Feng, W. Hu, Y. Jiao, L. Zhou, W. Zhang, Z. Hu and Y. Liu, J. Anal. At. Spectrom., 2020, 88, 293-310.

25 E. D. Young, C. E. Manning, E. A. Schauble, A. Shahar, C. A. Macris, C. Lazar and M. Jordan, Chem. Geol., 2015, 395, 176-195.

26 M. Blanchard, E. Balan and E. A. Schauble, Rev. Mineral. Geochem., 2017, 82, 27-63.

27 F. Farges, Geochim. Cosmochim. Acta, 1991, 55, 3303-3319.

28 M. Louvel, C. Sanchez-Valle, W. J. Malfait, D. Testemale and J.-L. Hazemann, Geochim. Cosmochim. Acta, 2013, 104, 281299.

29 K. Robinson, G. V. Gibbs and P. H. Ribbe, Am. Mineral., 1971, 56, 782-790.

30 D. K. Smith and W. Newkirk, Acta Crystallogr., 1965, 18, 983991.

31 P. W. Crohn and D. H. Moore, BMR J. Aust. Geol. Geophys., 1984, 9, 13-18.

32 S. E. M. Gain, Y. Gréau, H. Henry, E. Belousova, I. Dainis, W. L. Griffin and S. Y. O'Reilly, Geostand. Geoanal. Res., 2019, 3, 227-316.

33 M. Wiedenbeck, J. M. Hanchar, W. H. Peck, P. Sylvester, J. W. Valley, M. Whitehouse, A. Kronz, Y. Morishita, L. Nasdala, J. Fiebig, I. Franchi, J. P. Girard, R. C. Greenwood, R. Hinton, N. Kita, P. Mason, M. Norman, M. Ogasawara, R. Piccoli, D. Rhede, H. Satoh, B. Schulz-Dobrick, O. Skar, M. J. Spicuzza, K. Terada, A. Tindle, S. Togashi, T. Vennemann, Q. Xie and Y. F. Zheng, Geostand. Geoanal. Res., 2004, 28, 9-39.

34 M. H. Dodson, J. Sci. Instrum., 1963, 40, 289-295.

35 M. H. Dodson, J. Phys. E: Sci. Instrum., 1969, 2, 490-498.

36 S. J. G. Galer, Chem. Geol., 1999, 157, 255-274.
37 C. M. Johnson and B. L. Beard, Int. J. Mass Spectrom. Ion Phys., 1999, 193, 87-99.

38 F. Albarede and B. L. Beard, in Geochemistry of NonTraditional Stable Isotopes, ed. C. M. Johnson, B. L. Beard and F. Albarede, 2004, vol. 55, pp. 113-152.

39 J. F. Rudge, B. C. Reynolds and B. Bourdon, Chem. Geol., 2009, 265, 420-431.

40 A. J. Mayer and M. E. Wieser, J. Anal. At. Spectrom., 2014, 29, 85-94.

41 M.-A. Millet and N. Dauphas, J. Anal. At. Spectrom., 2014, 29, 1444.

42 F. Kurzweil, C. Münker, J. Tusch and R. Schoenberg, Chem. Geol., 2018, 476, 407-417.

43 K. L. Currie, J. Knutson and P. A. Temby, Contrib. Mineral. Petrol., 1992, 109, 326-339.

44 J. Mattinson, Chem. Geol., 2005, 220, 47-66.

45 P. Widmann, J. H. F. L. Davies and U. Schaltegger, Chem. Geol., 2019, 511, 1-10.

46 T. Meisel, J. Moser, N. Fellner, W. Wegscheider and R. Schoenberg, Analyst, 2001, 126, 322-328.

47 K. M. Samperton, B. Schoene, J. M. Cottle, C. Brenhin Keller, J. L. Crowley and M. D. Schmitz, Chem. Geol., 2015, 417, 322-340.

48 A. Kawashima, K. Takahashi and A. Masuda, Phys. Rev. C: Nucl. Phys., 1993, 47, R2452-R2456.

49 M. E. Wieser and J. R. De Laeter, Phys. Rev. C: Nucl. Phys., 2001, 64, 7.

50 J. Meija, T. B. Coplen, M. Berglund, W. A. Brand, P. De Bièvre, M. Gröning, N. E. Holden, J. Irrgeher, R. D. Loss, T. Walczyk and T. Prohaska, Pure Appl. Chem., 2016, 88, 252-314.

51 C. Münker, S. Weyer, E. Scherer and K. Mezger, Geochem., Geophys., Geosyst., 2001, 2, 19.

52 F. L. H. Tissot and N. Dauphas, Geochim. Cosmochim. Acta, 2015, 167, 113-143.

53 F.-Z. Teng, N. Dauphas and J. M. Watkins, Rev. Mineral. Geochem., 2017, 82, 1-26.

54 J. Vervoort, P. Patchett, U. Söderlund and M. Baker, Geochem., Geophys., Geosyst., 2004, 5, Q11002.

55 C. M. Fisher, J. M. Hanchar, S. D. Samson, B. Dhuime, J. Blichert-Toft, J. D. Vervoort and R. Lam, Chem. Geol., 2011, 286, 32-47.

56 M. Ibañez-Mejia, G. E. Gehrels, J. Ruiz, J. D. Vervoort, M. E. Eddy and C. Li, Chem. Geol., 2014, 384, 149-167.

57 M. Ibañez-Mejia, A. Pullen, J. Arenstein, G. E. Gehrels, J. Valley, M. N. Ducea, A. R. Mora, M. Pecha and J. Ruiz, Precambrian Res., 2015, 267, 285-310.

58 N. Dauphas and E. A. Schauble, Annu. Rev. Earth Planet. Sci., 2016, 44, 709-783.

59 N. Dauphas, A. Pourmand and F.-Z. Teng, Chem. Geol., 2009, 267, 175-184.

60 F. L. H. Tissot, M. Ibañez-Mejia, P. Boehnke, N. Dauphas, D. McGee, T. L. Grove and T. M. Harrison, J. Anal. At. Spectrom., 2019, 1-18.

61 I. Wendt and C. Carl, Chem. Geol., 1991, 86, 275-285.

62 K. Mahon, Int. Geol. Rev., 1996, 38, 293-303.

63 R. E. Criss, Principles of Stable Isotope Distribution, Oxford University Press, New York, 1999. 
64 D. J. Cherniak, J. M. Hanchar and E. B. Watson, Contrib. Mineral. Petrol., 1997, 127, 383-390.

65 J. Crank, The Mathematics of Diffusion, Oxford University Press, 2nd edn, 1975.

66 H. M. Kirkpatrick, T. M. Harrison, M.-C. Liu, E. A. Bell, F. L. H. Tissot and M. Ibañez-Mejia, In situ $\delta^{94 / 90} \mathrm{Zr}$ variations in zircon as an indicator of magmatic differentiation, AGU Fall Meeting, San Francisco, December 2019.

67 J. Valley and N. Kita, Mineral. Assoc. Can., Short Course Ser., 2009, 41, 19-63.
68 L. Nasdala, M. Zhang, U. Kempe, G. Panczer, M. Gaft, M. Andrut and M. Plötze, in Zircon, ed. J. M. Hanchar and P. W. O. Hoskin, Mineralogical Society of America, 2003, vol. 53, pp. 427-467.

69 W. R. Guenthner, P. W. Reiners, R. A. Ketcham, L. Nasdala and G. Giester, Am. J. Sci., 2013, 313, 145-198.

70 M. H. Dodson, Geochim. Cosmochim. Acta, 1970, 34, 12411244.

71 M. Schönbächler, M. Rehkämper, D.-C. Lee and A. N. Halliday, Analyst, 2004, 129, 32. 